\title{
Tournefortia L. (Boraginaceae): espécies do Brasil extra-amazônico ${ }^{1}$
}

\author{
Larissa Cavalheiro ${ }^{2,5}$, Neusa Taroda Ranga ${ }^{3}$ e Antonio Furlan ${ }^{4 *}$
}

Recebido: 3.04.2008; aceito: 26.05.2011

\begin{abstract}
Tournefortia L. (Boraginaceae): extra Amazonian Brazilian species). Tournefortia has about 150 species distributed in warm regions of the world, especially in the Neotropics. In this study all Brazilian species of Tournefortia, except those from the Amazonian region, are treated. Two sections, Tournefortia and Cyphocyema, with 15 species and one variety were found. It was previously known only to southwestern Brazil. Keys, descriptions, comments on morphological taxonomic characters and geographic distribution are also provided.
\end{abstract}

Key words: neotropics, taxonomy treatment, Tournefortia

RESUMO - (Tournefortia L. (Boraginaceae): espécies do Brasil extra-amazônico). Tournefortia possui cerca de 150 espécies distribuídas nas regiões quentes do mundo, principalmente nos Neotrópicos. Está sendo fornecido o tratamento necessário para identificação das espécies de Tournefortia para o Brasil, exceto região Amazônica, incluindo chaves taxonômicas e descrições. Foram encontradas as duas secções: Tournefortia e Cyphocyema, abrangendo 15 espécies e uma variedade. São apresentados comentários sobre a morfologia dos caracteres utilizados na identificação e distribuição geográfica. Palavras-chave: neotrópicos, Tournefortia, tratamento taxonômico

\section{Introdução}

O gênero Tournefortia descrito por Linnaeus em 1753, pertence à família Boraginaceae, e está inserido na subfamília Heliotropioideae junto com Heliotropium, diferenciando deste principalmente pelo hábito lenhoso, fruto drupáceo e também, pela corola com lobos reflexos (Gentry 1977) e por apresentar sementes sem endosperma e estilete inteiro (Lawrence 1937). Apresenta cerca de 150 espécies distribuídas nas regiões quentes do mundo, a maioria nos neotrópicos (Miller 1988). Segundo Johnston (1930), 15 destas espécies ocorrem na América do Sul e estão divididas em duas secções: Sect. Tournefortia, quando apresenta o embrião reto, e frutos obscuramente lobados, e Sect. Cyphocyema com frutos 4-lobados portando sementes com embrião curvo, sendo esta última com grande representatividade em todo o território brasileiro. Entretanto, alguns dos seus táxons apresentam problemas de delimitação, provavelmente refletidos pela plasticidade relacionada ao espectro de distribuição e, consecutivamente, de habitats nos quais se estabelecem (Melo 2007).

Dada esta condição, Diane et al. (2002) em estudos moleculares associados à morfologia da subfamília Heliotropioideae observou que Tournefortia é polifilético enquanto que Heliotropium seria parafilético colocando em dúvida a atual posição destes gêneros, e, portanto, sugerindo mudanças nomenclaturais e taxonômicas para os dois grupos. Aliado a isso, enfatiza-se a necessidade de estudos de base taxonômicos para a confirmação da identidade das espécies e sua real distribuição.

1. Parte da dissertação de mestrado da primeira autora pelo Curso de Pós-graduação em Biologia Vegetal, UNESP, Campus de Rio Claro, Avenida 24-A n. 1515, 13506-900 Rio Claro, SP, Brasil

2. Universidade Federal de Mato Grosso, Campus Universitário de Sinop, Instituto de Ciências Naturais, Humanas e Sociais, Av. Alexandre Ferronato 1200, 78557-267 Sinop, MT, Brasil

3. Universidade Estadual Paulista, Campus de São José do Rio Preto, Departamento de Zoologia e Botânica, Rua Cristóvão Colombo 2265, 15054-000 São José do Rio Preto, SP, Brasil

4. Universidade Estadual Paulista, Campus de Rio Claro, Instituto de Biociências, Departamento de Botânica, Avenida 24-A n.1515, 13506-900 Rio Claro, SP, Brasil. *In memorian

5. Autor para correspondência: larissacavalheiro@ufmt.br 
Para o Brasil, o primeiro trabalho de amplitude nacional foi o de Fresenius (1857) reconhecendo 26 espécies nativas. Os trabalhos recentes tratam o gênero em estudos regionais ou em listas de floras que geralmente englobam um número reduzido de espécies como: Andrade-Lima (1953-1954) para o estado de Pernambuco; Smith (1970) para Santa Catarina; Melo \& Andrade (2007), Melo et al. (2007), Melo et al. (2008) para a região nordeste do país, principalmente nas áreas de semi-árido; Guimarães et al. (1971) para o Rio de Janeiro; Vitta (1992) para Minas Gerais; Nagatani \& Rossi (2000), Taroda \& Silva (2002), Cavalheiro et al. (2003) para São Paulo. Observa-se uma maior concentração de trabalhos para as regiões Sul e Sudeste do país enquanto que nas demais regiões os estudos praticamente inexistem.

O presente trabalho tem como objetivo o estudo taxonômico das espécies de Tournefortia para o Brasil, excetuando-se à região amazônica, fornecendo, assim, o tratamento necessário para identificação destas espécies.

\section{Material e métodos}

Este trabalho foi realizado principalmente através do estudo de cerca de 1300 exsicatas provenientes dos diversos herbários do país e do exterior: ASE, $\mathrm{BAH}, \mathrm{BHCB}, \mathrm{CEN}, \mathrm{CH}, \mathrm{COR}, \mathrm{EAC}, \mathrm{ESA}, \mathrm{ESAL}$, FUEL, HB, HEPH, HRB, HRCB, HUEFS, HUFU, IAC, IBGE, INPA, IPA, MAC, MBML, MO, NY, PACA, PEL, PEUFR, R, RB, SJRP, SP, SPF, SPSF, TEPB, UB, UEC, UFG, UFJF e VIC, complementados por coletas realizadas no Estado de São Paulo.

Foram analisadas exsicatas de espécimes amazônicos (Estados do Acre, Amapá, Amazonas, Pará, Rondônia e Roraima), entretanto estes não foram incluídos haja vista, que, esta região apresenta-se mal amostrada.

O material foi analisado através de estereomicroscópio e as estruturas florais, quando retiradas do material herborizado, foram reidratadas em água fervente contendo $10 \mathrm{ml}$ de água sanitária para clarificar as estruturas ou, ainda, conservadas em álcool 70\% para estudos posteriores. A descrição das espécies foi realizada por análises quantitativas e qualitativas das estruturas e baseadas em Hickey \& King (2002); os dados morfológicos obtidos foram inventariados e utilizados na confecção da chave analítica.

As descrições foram baseadas, principalmente, na comparação com exsicatas e na literatura referenciada. Não foi realizada discussão da validade das sinonímias, pois não foi possível examinar os materiais-tipo sendo que, algumas vezes, as descrições originais omitiam informações imprescindíveis. No tratamento taxonômico foram incluídos dados de distribuição geográfica, dados de floração, frutificação e relativos ao habitat em que os espécimes foram encontrados além de desenhos e/ou fotografias das espécies.

As ilustrações foram realizadas em nanquim a partir de estereomicroscópio acoplado com uma câmara clara além da observação direta do material, herborizado ou na natureza. As informações referentes ao ambiente, distribuição geográfica e fenologia reprodutiva foram compiladas das etiquetas de herbário que acompanham o material examinado e da literatura.

\section{Resultados e Discussão}

As espécies de Tournefortia apresentam hábito variado. São caracterizadas pelo porte arbustivo (arbustos e subarbustos), escandentes ou não ou lianas e, em alguns poucos casos, arvoretas. A altura varia de menos de $1 \mathrm{~m}$ (herbáceas) a $5 \mathrm{~m}$ (arbustos), entretanto, alguns espécimes atingem cerca de $8 \mathrm{~m}$. Neste gênero o caule apresenta-se, no aspecto geral, praticamente uniforme tanto nos arbustos quanto nas lianas. Entretanto em T. andrade-limae J.I.M. Melo, T. rubicunda Salzm. ex DC. e T. salzmannii DC. o caule apresenta lenticelas, constituindo um atributo adicional na identificação dessas. Quanto à pilosidade dos ramos, estes podem apresentar-se de glabros a pilosos. Os ramos da inflorescência nunca são glabros, e possuem desde uma pubescência esparsa até um indumento densamente tomentoso. Esse caráter geralmente é relevante na identificação das diferentes espécies.

As folhas são dispostas alternadamente ao redor do eixo caulinar; simples, inteiras e sem estípulas. $\mathrm{O}$ pecíolo é, em todas as espécies estudadas, levemente canaliculado e não achatado, variando apenas quanto ao seu comprimento e espessura, contribuindo pouco na distinção das espécies. Podem ser delgados e longos (atingindo até $2 \mathrm{~cm}$ de comprimento) ou robustos e mais curtos (variando de poucos milímetros e geralmente não atingindo $1 \mathrm{~cm}$ ). A pilosidade também varia de esparsos tricomas a indumento densamente tomentoso. Os tricomas são sempre simples. A forma do limbo é variável e foi classificada de acordo com Hickey \& King (2002). Os tricomas na superfície adaxial e abaxial constituem um caráter importante 
na distinção das espécies. Em T. rubicunda e T. melanochaeta DC. apresentam-se com as bases dilatadas. Podem ser glabros como em T. bicolor Sw. a tomentosos/escabros como em T. villosa Salzm. ex DC. (tricomas e escalas baseados em Hickey \& King (2002)).

A inflorescência é do tipo cimeira escorpióide, pouco ramificadas a densamente ramificadas formando ramos secundifloros. Não ocorrem brácteas, diferindo neste aspecto do gênero Heliotropium Sect. Orthostachys R. Br. Podem ser axilares como em T. breviflora DC. ou terminais, nas demais espécies ou, ainda, lateralmente dispostas nos ramos em algumas espécies: T. rubicunda e T. gardneri A. DC., caráter pouco estudado e ainda não citado para o gênero. Apresentam cimas de comprimento variável, que são mais curtos em T. villosa, T. gardneri e T. salicifolia (Gardn.) DC., nos quais as flores estão agregadas de modo a formar "cachos", constituindo-se um excelente caráter taxonômico; ou então, mais longos com suas flores dispostas laxamente nas demais espécies. Quanto à pilosidade dos ramos, somente em $T$. bicolor estes apresentam-se glabrescentes, sendo nas demais espécies, tomentosos.

As flores são sempre hermafroditas, diclamídeas, pentâmeras, actinomorfas, sésseis ou subsésseis. O cálice é gamossépalo com tubo muito curto, às vezes com a união de suas sépalas apenas próximas à base. Possui lobos geralmente lineares ou curto-lanceolados. Varia no comprimento: atingindo a extremidade do tubo, como em T. candidula (Miers) I.M. Johnst., T. gardneri, T. melanochaeta, T. salicifolia e T. villosa ou, ainda, até a metade do tubo da corola nas demais espécies. A corola é gamopétala de variadas colorações: brancas, amarelas ou esverdeadas como as mais comuns; até vermelhas, ferrugíneas a alaranjadas, roxa ou lilás a azul como variações mais extremas. O tubo é geralmente cilíndrico, às vezes dilatado na base; os lobos são largamente curtolanceolados podendo chegar a longo-ligulados. O tamanho relativo do tubo em relação aos lobos da corola varia inter-especificamente, por exemplo, em T. paniculata Cham., o tubo é evidentemente longo com lobos curto-lanceolados. Os tricomas estão, em geral, presentes no cálice e na corola, entretanto, em T. breviflora apresentam-se menos densos e em T. bicolor são glabrescentes.

O androceu é constituído por 5 estames inclusos, sésseis ou subsésseis, inseridos na extremidade do tubo da corola ou na porção mediana do tubo
(T. bicolor). As anteras livres ou coerentes, na maioria das espécies, são lanceoladas, ovadas ou lineares e não atingem $2 \mathrm{~mm}$ de comprimento.

O ovário é sempre 2-carpelar, falsamente 4-locular e 1-ovulado (em raros espécimes verificou-se ser 2-ovulado). O estilete é único e varia em comprimento interespecificamente, ou então, apresenta-se séssil (T. angustiflora Ruiz \& Pav. e T. bicolor) com o estigma inserido diretamente no ovário. O estigma possui um anel que varia em espessura sendo muito evidente, como em T. paniculata ou inconspícuo, em T. membranacea A. DC.; o ápice é cônico-triangular curto como em T. volubilis L., alongado como em $T$. candidula ou até mesmo globoso em T. maculata Jacq.; constituindo-se, assim, num excelente caráter distintivo das espécies. Ao analisar os estigmas notam-se, quatro grupos de espécies: Grupo 1- Gineceu com estigma séssil; Grupo 2- Gineceu com estigma de ápice globoso, estilete longo; Grupo 3- Gineceu com estigma de ápice cônico-triangular curto; Grupo 4- Gineceu com estigma de ápice cônico-triangular alongado (Tabela 1). Embora não se tenha analisado as flores de T. angustiflora, de acordo com a literatura já citada, esta pertence ao Grupol (junto de T. bicolor). T. melanochaeta, T. paniculata (incluindo a variedade) e T. maculata formam um grupo à parte por apresentarem o ápice estigmático globoso e anel estigmático evidente com notável pilosidade (Grupo 2). As espécies do Grupo 3, além de possuírem ápice estigmático cônico-triangular curto, T. andrade-limae, T. volubilis e T. salzmannii apresentam o anel do estigma evidente, sendo, nas demais, inconspícuo. Nas plantas do Grupo 4 parece haver uma correlação entre formato do ápice estigmático e espessura do anel: todas as plantas com ápice do estigma alongado, possuem o anel evidente. Para as espécies destes dois grupos (3 e 4) podemos ressaltar ainda que o ápice estigmático pode ser evidentemente ou obscuramente 4-lobado, caráter adicional na separação das espécies. Essas são conclusões primárias uma vez que foram analisados poucos materiais de algumas espécies, entretanto, foi considerada, neste trabalho, a adoção desses grupos para analisar as relações interespecíficas e utilizar como critério na separação das espécies. Acredita-se, ainda, pelas semelhanças entre as espécies pertencentes aos grupos, a sugestão da proximidade entre estas, sugere-se, no entanto, a realização de estudos filogenéticos para confirmar essas especulações evolutivas. 
Tabela 1. Quadro comparativo das espécies e respectivos tipos de gineceu.

Table 1. Comparative table of species and their carpels.

\begin{tabular}{|c|c|c|c|c|c|c|}
\hline & \multirow[t]{2}{*}{$\begin{array}{c}\text { Grupo } 1 \\
\text { Estigma séssil }\end{array}$} & \multirow[t]{2}{*}{$\begin{array}{c}\text { Grupo } 2 \\
\text { Estigma com } \\
\text { ápice globoso }\end{array}$} & \multicolumn{2}{|c|}{$\begin{array}{c}\text { Grupo } 3 \\
\text { Estigma com } \\
\text { ápice cônico-triangular curto }\end{array}$} & \multicolumn{2}{|c|}{$\begin{array}{c}\text { Grupo } 4 \\
\text { Estigma com } \\
\text { ápice cônico-triangular alongado }\end{array}$} \\
\hline & & & $\begin{array}{l}\text { Evidentemente } \\
\text { 4-lobado }\end{array}$ & $\begin{array}{c}\text { Obscuramente } \\
\text { 4-lobado }\end{array}$ & $\begin{array}{l}\text { Evidentemente } \\
\text { 4-lobado }\end{array}$ & $\begin{array}{c}\text { Obscuramente } \\
\text { 4-lobado }\end{array}$ \\
\hline T. andrade-limae & & & & $\mathrm{X}$ & & \\
\hline T. angustiflora & $\mathrm{X}$ & & & & & \\
\hline T. bicolor & $\mathrm{X}$ & & & & & \\
\hline T. breviflora & & & & $\mathrm{X}$ & & \\
\hline T. candidula & & & & & & $\mathrm{X}$ \\
\hline T. gardneri & & & & & & \\
\hline T. melanochaeta & & $\mathrm{X}$ & & & & \\
\hline T. membranacea & & & $\mathrm{X}$ & & & \\
\hline T. paniculata & & $X$ & & & & \\
\hline T. rubicunda & & & & & $\mathrm{X}$ & \\
\hline T. salicifolia & & & & & $\mathrm{X}$ & \\
\hline T. salzmannii & & & $\mathrm{X}$ & & & \\
\hline T. maculata & & $\mathrm{X}$ & & & & \\
\hline T. villosa & & & & $\mathrm{X}$ & & \\
\hline T. volubilis & & & $\mathrm{X}$ & & & \\
\hline
\end{tabular}

O fruto, uma drupa, pode ser evidente ou obscuramente 4-lobado; apresenta-se piloso (T. candidula, T. gardneri, T. melanochaeta, T. salicifolia e T. villosa) ou glabro (demais espécies), servindo assim como um caráter adicional na separação das espécies. Quando imaturos são verdes ou esbranquiçados e maduros apresentam-se amarelos, laranjas até mesmo vermelhos, raro brancos; com ou sem manchas negras. O embrião pode ser curvo ou retilíneo, mas essa estrutura é de difícil visualização no material conservado (herborizado) embora relevante na separação das secções do gênero: Tournefortia I.M. Johnst. e Cyphocyema I.M. Johnst.

Os dados apresentados na tabela 2 são referentes à distribuição geográfica geral das espécies analisadas. De acordo com os dados obtidos podemos dividir artificialmente as espécies em quatro grandes grupos: Grupo 1-Espécies amplamente distribuídas: T. bicolor, T. breviflora, T. membranacea, T. paniculata, T. rubicunda, T. maculata, T. villosa. Grupo 2- Espécies restritas à região Nordeste: T. andradelimae, T. candidula, T. melanochaeta, T. salzmannii. Grupo 3- Espécies restritas ao eixo Sul-Sudeste: T. gardneri, T. salicifolia, T. volubilis. Grupo 4Espécies restritas à região Centro-Oeste: T. angustiflora. Ao observarmos os mapas de distribuição das espécies notamos que, provavelmente, as espécies restritas estão associadas a climas e/ou tipos vegetacionais característicos de cada região. Possivelmente as espécies do Grupo 2 são plantas adaptadas ao clima quente e seco característico da região Nordeste, distribuindo-se pelos ambientes de caatinga. As espécies do Grupo 3 correspondem aos climas mais amenos (até mesmo climas frios) característicos das regiões Sul e Sudeste e distribuem-se, principalmente, em ambientes de Mata Atlântica e pequenos fragmentos de mata primária ou secundária. $T$. angustiflora pode ser considerada como um caso a parte (Grupo 4). Apesar de ter sido encontrada no ambiente de cerrado, não é possível fazer muitas inferências sobre esta espécie haja vista a escassez de coleções para a espécie nesse estudo (apenas dois espécimes).

A região Sudeste possui o maior número de espécimes coletados, sendo assim uma das regiões brasileira melhor conhecida já que o esforço amostral foi maior em relação às demais. Enquanto isso, as outras regiões (Norte, Nordeste, Centro-Oeste e Sul) continuam com poucos espécimes registrados, sendo pouco definidos os representantes das diversas flórulas regionais. Por fim, a distribuição de Tournefortia ainda apresenta lacunas havendo a necessidade urgente de se realizar outros estudos e um expressivo 
esforço amostral por parte dos pesquisadores das diversas localidades do país para o conhecimento real da fitodiversidade brasileira.

Para as regiões Sul, Sudeste, Centro-Oeste e Nordeste do Brasil foram registradas duas secções (Tournefortia e Cyphocyema), com 15 espécies de Tournefortia e uma variedade intraespecífica. Apesar de terem sido analisadas cerca de 1300 exsicatas, estas nem sempre são muito representativas, pois algumas espécies apresentam grandes amostras enquanto que outras possuem apenas 1 ou 2 espécimes. Enfatiza-se, assim, a necessidade de um maior número de coletas, pois o número de espécies encontradas (15 espécies) perfaz apenas $10 \%$ das ocorrentes nas regiões quentes do mundo (150 espécies). O Brasil, por ser um país tão extenso e com uma grande variedade de tipos vegetacionais associados aos ambientes e climas, pode apresentar um número maior de espécies que o apresentado.

Tournefortia L. Sp. P1.: 140. 1753.

Tipo: T. hirsutissima L., Sp. P1.: 140. 1753 (nom. et typ. cons. Taxon 44: 611-612. 1995)

Chave para as espécies brasileiras extra-amazônicas de Tournefortia

1. Estames com anteras livres; fruto obscuramente lobado; embrião reto 3. T. bicolor

1. Estames com anteras coerentes; fruto evidentemente lobado; embrião curvo

2. Gineceu com estigma séssil. 1. T. angustiflora

2. Gineceu com estigma e estilete

3. Ramos da planta com lenticelas

4. Folhas com face abaxial glabrescente a pilosa, tricomas com bases dilatadas

10. T. rubicunda

4. Folhas com face abaxial estrigosa a tomentosa, tricomas sem bases dilatadas

5. Inflorescência escorpióide ramificada (secundifloras), cima menor que $4 \mathrm{~cm}$

1. T. andrade-limae

5. Inflorescência escorpióide, sem ramos secundifloros, cima maior que $4 \mathrm{~cm}$ 14. T. salzmannii

3. Ramos da planta sem lenticelas

6. Inflorescência axilar

4. T. breviflora

6. Inflorescência terminal

7. Flores laxamente dispostas nos ramos

8. Tubo da corola curto, até $3 \mathrm{~mm}$

15. T. volubilis

8. Tubo da corola longo, maior que $3 \mathrm{~mm}$

9. Superfície abaxial das folhas pubescente; folhas com ápice acuminado

9. Superfície abaxial pubérula; folhas com ápice cuspidado a caudado.....

9. T. paniculata

9. Superfície abaxial pubérula; folhas com
7. Flores mais ou menos agregadas a agregadas

10. Anel estigmático evidente

11. Ápice estigmático globoso

7. T. melanochaeta

11. Ápice estigmático cônico-triangular

12. Superfície abaxial das folhas vilosa, tricomas esbranquiçados ou cinéreos

13. T. maculata

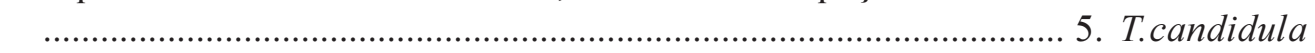

12. Superfície abaxial das folhas tomentosa, tricomas amarelos ou dourados

11. T.salicifolia

10. Anel estigmático inconspícuo

13. Frutos glabros

8. T. membranacea

13. Frutos pubescentes a estrigosos

14. Subarbustos ou arbustos escandentes até $1 \mathrm{~m}$; face abaxial das folhas densamente dourado vilosa 6. T. gardneri

14. Cipós ou arbustos escandentes até $3 \mathrm{~m}$; face abaxial amarelo-tomentosa 14. T. villosa 
Tabela 2. Distribuição geográfica das espécies de Tournefortia.

Table 2. Geographic distribution of Tournefortia species.

\begin{tabular}{|c|c|c|}
\hline Espécie & Brasil & Outros países (América) \\
\hline T. andrade-limae & $\mathrm{PB}$ & \\
\hline T. angustiflora & MT, GO & $\begin{array}{l}\text { Belize, Equador, El Salvador, Estados Unidos da América, } \\
\text { Guatemala, Honduras, México, Panamá, Peru, Venezuela }\end{array}$ \\
\hline T. bicolor & $\begin{array}{l}\text { AL, AM, BA, CE, ES, GO, MG, } \\
\text { MT, PA, PB, PE, PR, RJ, RO, RR, } \\
\text { SC, SE, SP, TO }\end{array}$ & $\begin{array}{l}\text { Belize, Bolívia, Equador, Guatemala, Guiana, Guiana Francesa, } \\
\text { Honduras, México, Panamá, Peru, Suriname, Venezuela. }\end{array}$ \\
\hline T. breviflora & $\begin{array}{l}\text { AL, BA, DF, ES, GO, MG, PE, PR, } \\
\text { RJ, RS, SC, SP, TO }\end{array}$ & Argentina, Peru. \\
\hline T. candidula & $\mathrm{BA}, \mathrm{CE}, \mathrm{MA}, \mathrm{PA}, \mathrm{PE}, \mathrm{RJ}, \mathrm{SP}, \mathrm{RN}$ & Guiana, Venezuela. \\
\hline T. volubilis & RJ & $\begin{array}{l}\text { Belize, Caribe, El Salvador, Estados Unidos da América, } \\
\text { Guatemala, Honduras, México, Nicarágua, Panamá, Venezuela }\end{array}$ \\
\hline T. gardneri & BA, ES, PR, RJ, SC, SP & Argentina, Equador \\
\hline T. melanochaeta & $\mathrm{BA}$ & Guiana, Guiana Francesa \\
\hline T. membranacea & $\begin{array}{l}\text { BA, CE, ES, GO, MG, PE, RJ, RS, } \\
\text { SC, SP }\end{array}$ & Argentina \\
\hline T. paniculata & $\begin{array}{l}\text { BA, CE, DF, ES, GO, MG, MT, PE, } \\
\text { PR, RJ, RS, SC, SP, TO }\end{array}$ & Argentina, Bolívia, Guiana, Guiana Francesa, Suriname. \\
\hline T. paniculata var. austrina & BA & Argentina, Bolívia. \\
\hline T. rubicunda & $\begin{array}{l}\text { AL, AM, BA, CE, DF, ES, GO, MG, } \\
\text { MS, MT, PB, PE, PR, RJ, RS, SP }\end{array}$ & Argentina, Bolívia, Paraguai. \\
\hline T. salicifolia & $\mathrm{GO}, \mathrm{MG}, \mathrm{PR}, \mathrm{RJ}, \mathrm{RS}$ & \\
\hline T. salzmanii & BA, CE, ES, PE, PI, RJ, RO & Argentina, Bolívia, Paraguai. \\
\hline T. maculata & $\mathrm{AC}, \mathrm{AM}, \mathrm{GO}, \mathrm{MG}, \mathrm{RJ}, \mathrm{TO}$ & Bolívia, Guiana. \\
\hline T. villosa & $\begin{array}{l}\text { BA, ES, MG, PI, PE, PR, RJ, RS, } \\
\text { SC, SE, SP }\end{array}$ & \\
\hline
\end{tabular}

1. Tournefortia andrade-limae J.I.M. Melo, Hoehnea 34(2): 155. 2007.

Arbusto escandente; ramos glabros a pubérulos com lenticelas acastanhadas. Folhas ovadas 3,4-3,5 cm $\times 1,1-1,3 \mathrm{~cm}$, membranáceas, levemente discolores, ápice cuspidado, base arredondada, margem inteira a levemente ondulada; face adaxial e abaxial estrigosas; pecíolo curto 3-4 $\mathrm{mm}$. Inflorescências terminais ou axilares, escorpióides, cimas curtas ramificadas, laxamente dispostas, 2,3-3,7 cm. Flores alvas, cerca de $4 \mathrm{~mm}$; cálice subséssil ou pedicelado, menor ou alcançando o comprimento da corola, pubescente, lobos lanceolados somente unidos na base, 2,3-2,5 mm $\times 0,2-0,4 \mathrm{~mm}$; corola vilosa externamente, tubo cilíndrico alongado 4,4-4,7 mm, lobos lineares, cerca de $1 \mathrm{~mm}$; anteras coerentes, ovóides-triangulares, inseridas na extremidade do tubo da corola, $2 \mathrm{~mm}$; gineceu 2-3 $\mathrm{mm}$, estigma com anel estigmático evidente, ápice estigmático cônico-triangular curto, obscuramente 4-lobado, estilete curto cerca de $1,3 \mathrm{~mm}$. Frutos não observados.

Material selecionado: BRASIL. PaRAíba: São José dos Cordeiros, VI-1997, Braz s.n. (IPA53027).
T. andrade-limae é reconhecida pelas suas folhas arredondadas na base e inflorescências densamente ramificadas. É morfologicamente similar a T. rubicunda diferindo desta pelas inflorescências densas, flores subsésseis ou pediceladas, anteras ovado-triangulares com cerca de $1 \mathrm{~mm}$ enquanto que T. rubicunda apresenta inflorescência laxa, flores sésseis e anteras lanceoladas com cerca de $0,8 \mathrm{~mm}$ (Melo 2007).

Esta espécie foi recentemente descrita e é conhecida, até o momento, somente no Estado da Paraíba, associada à vegetação de caatinga. Floração observada somente no mês de junho.

2. Tournefortia angustiflora Ruiz \& Pav., Fl. Peruv. 2: 25, t. 151. 1799.

Figura 2 a-d.

Liana sobre árvore ou arbusto decumbente, até $2 \mathrm{~m}$; ramos pubérulos a levemente pubescentes. Folhas lanceoladas a oblongo-lanceoladas $6,5-11,0 \mathrm{~cm}$ $\times 3,5-5,5 \mathrm{~cm}$, ápice cuspidado, base acuminada ou obtusa, margem inteira; face adaxial glabrescente e face abaxial pubescente com concentração dos 
tricomas nas nervuras; pecíolo 1-2 cm. Inflorescência terminal, escorpióide, cimas longas até $6 \mathrm{~cm}$, laxas. Flores sésseis, pubescentes, alvas, brancas a amarelas, muitas vezes maiores que $1 \mathrm{~cm}$; cálice glabro a esparsamente estrigoso, lobos ovados; corola glabra a esparsamente estrigosa, tubo muito longo, lobos curtos, lanceolados; anteras coerentes, lanceoladas, inseridas na extremidade do tubo da corola; gineceu com estigma séssil, anel estigmático evidente, ápice cônico-triangular curto, evidentemente 4-lobado. Frutos imaturos, amarelos, $6 \mathrm{~mm}$, fortemente 4-lobados, glabros, embrião curvo.

Material examinado: BRASIL. GoIÁs: S/ município, V-1980, S. Doi et al. 5043 (HRB). Mato Grosso: Cuiabá, XI-1982, J.U. Santos et al. 535 (CH, HRB).

T. angustiflora é facilmente reconhecida por suas flores grandes (às vezes maiores que $1 \mathrm{~cm}$ ) e sua corola tubular (cilíndrica). É vegetativamente similar a T. bicolor diferindo desta por ter a superfície abaxial pubescente. O material analisado não apresentava flores sendo parte de sua descrição baseada em Nowicke (1969), Gibson (1970) e Miller (1988). Nowicke (1969), após a análise dos tipos, trata T. billbergiana Beurl. como um sinônimo taxonômico de T. angustiflora.

Está amplamente distribuída nas florestas úmidas do sul do México, Honduras ao Panamá, noroeste da América do Sul e Peru, ocorrendo do nível do mar atingindo $600 \mathrm{~m}$ de altitude (Miller 1988, Renner et al. 1990, Jorgensen et al. 1999, Balick et al. 2000, Linares et al. 2003, Hokche 2008. No Brasil foi coletada nos Estado de Goiás e Mato Grosso, em cerrado. A existência de apenas duas amostras não permite inferir sua distribuição exata para o país. Floração observada nos meses de maio e novembro.

3. Tournefortia bicolor Sw., Prodr. 9: 40. 1788.

Figura 1 a-b, 2 e-n.

Arbustos ou subarbustos, escandentes ou prostrados, lianas ou até mesmo arvoretas até $4 \mathrm{~m}$; ramos glabros a glabrescentes. Folhas lanceoladas, ovadas, ovaladas ou elípticas $(2,5) 4,0-10,5(15,5) \mathrm{cm}$ $\times(1,0)$ 2,0-4,5 $(7,0) \mathrm{cm}$, discolores, ápice agudo, cuspidado a caudado, base aguda ou acuminada, margem inteira ou levemente ondulada; face adaxial geralmente glabra ou glabrescente, raramente pubérula-hirtela, face abaxial glabrescente; pecíolo 1-2 cm. Inflorescência terminal escorpióide, cimas geralmente curtas 1,5-3,0 cm, laxamente dispostas.
Flores brancas a amarelas, 0,6-1,2 cm; cálice séssil, pubescente, tubo ausente ou com lobos somente unidos na base não alcançando $0,5 \mathrm{~mm}$, lobos 1-2 mm; corola pubescente, tubo cilíndrico alongado 4-9 mm, lobos largamente ovados, 1,5-3,0 mm; anteras livres, lanceoladas, inseridas até a metade do tubo da corola, 1-2 mm; gineceu curto 1-2 mm, estigma séssil com anel estigmático evidente, ápice cônico-triangular curto, evidentemente 4-lobado. Frutos imaturos verdes e maduros brancos, 3-7 mm, obscuramente 4-lobados, glabros, embrião reto.

Material selecionado: BRASIL. Alagoas: Viçosa, XI-1982, R.P. Lyra-Lemos et al. 767 (MAC). BAHIA: Aurelino Leal, II-1993, J.A. Kallunki et al. 413 (SP, SPF). CEARÁ: Aratuba, X-1978, A. Fernandes s.n. (EAC4151). Espírito SAnto: Cachoeiro do Itapemirim, XII-1994, J.R. Pirani et al. 3536 (SPF). GoIÁs: Caiaponia, VI-1966, H.S. Irwin et al. s.n. (NY17883, UB17493). MinAS Gerais. Lavras, XI-1998, A. Oliveira s.n. (SJRP20601). Mato Grosso: Pontes e Lacerda, IX-1997, A.G. Nave et al. 2019 (UEC). Pernambuco, Inajá, VIII-1994, M.J.N. Rodal et al. 346 (UEC). PARAnÁ, Diamante do Norte, IX-1998, J.M. Silva et al. 2536 (INPA, MBML); RIO DE JANEIRO, Silva Jardim, IX-1977, G. Martinelli et al. 2857 (SJRP, RB). SANTA Catarina: Guaramirim, IX-1947, H. Dalibour 196 (R). São Paulo: São Sebastião, IV-2000, W. Foster et al. 284 (SPF, UEC). TOCANTINS: Missão, II-1944, A. Ducke 1569 (RB).

Material adicional selecionado: BRASIL. AmAzonAs: Manaus, VIII-1996, P. Acevedo-Rodriguez et al. 8048 (INPA). PARÁ: Paraná de Almcirim, VI-1919, A. Ducke s.n. (RB11408). Roraima: Canto Galo, I-1967, G.T. Prance et al. 3990 (INPA, NY). VENEZUELA: MeridA, Zea, XI-1979, A. Quintero et al. 2255 (SP).

T. bicolor é facilmente reconhecida por suas folhas discolores, glabras ou glabrescentes, inflorescência distintamente escorpióide e pelo estigma séssil. Outra característica marcante é o embrião reto, posicionando-a na secção Tournefortia. São indicadas nas exsicatas, flores vináceas ou azuis, podendo revelar apenas estados de maturação das flores uma vez que somente foram observadas em campo apenas flores alvas. O material amazônico desta espécie difere quanto às folhas pubérulas e pelas flores densamente estrigosas, maiores. 

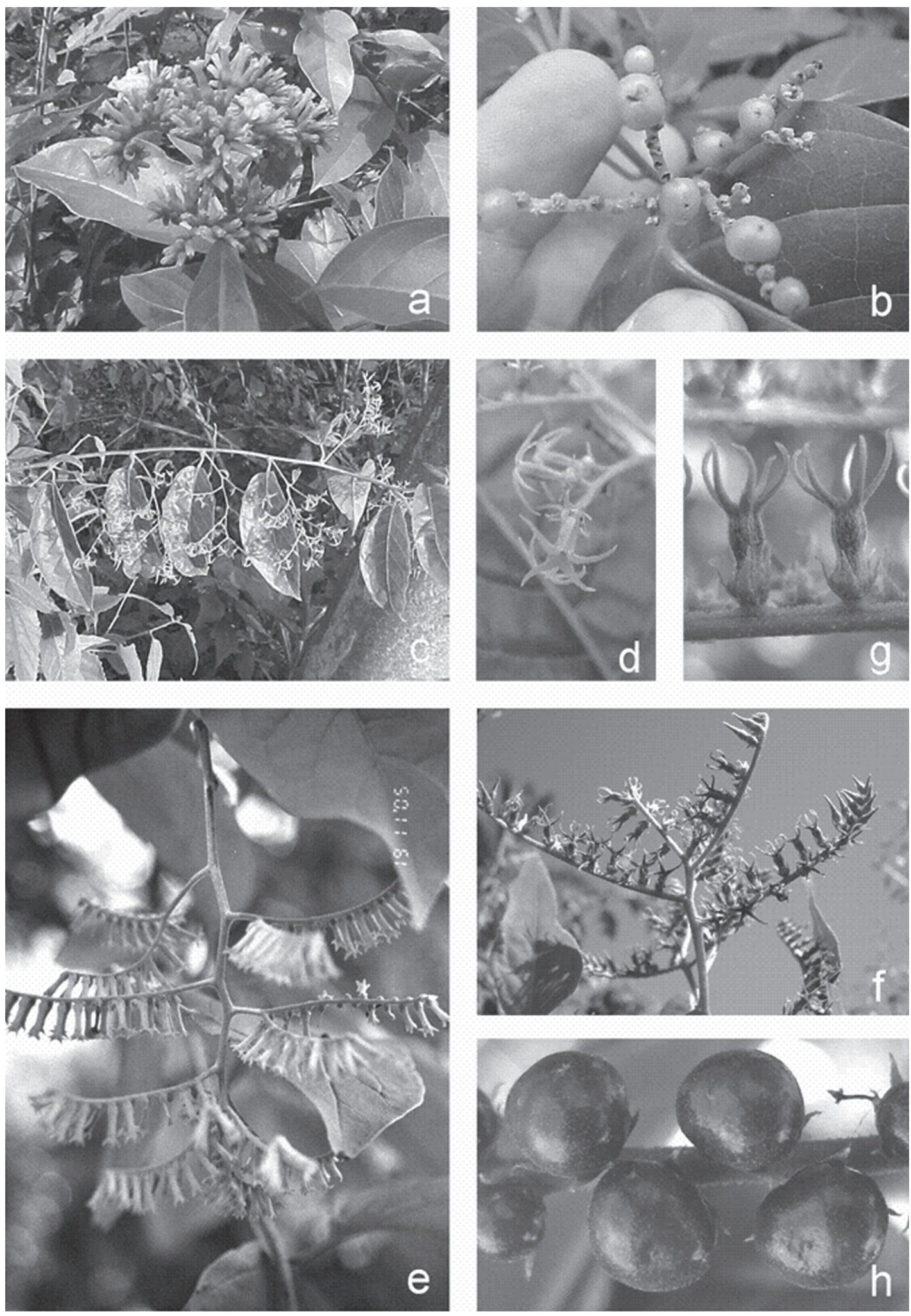

Figura 1. Espécies de Tournefortia do Brasil extra-amazônico. a-b. Tournefortia bicolor. a. Hábito. b. Fruto. c-d. Tournefortia breviflora. c. Hábito. d. Flor. e. Tournefortia paniculata. e. Hábito. f-h. Tournefortia rubicunda. f. Inflorescência. g. Flores. h. Fruto (Fotos: e. M.W.S. Lucas, demais D.F. Peralta).

Figure 1. Extra-amazonian Brazilian species of Tournefortia. a-b. Tournefortia bicolor. a. Habit. b. Fruit. c-d. Tournefortia breviflora. c. Habit. d. Flower. e. Tournefortia paniculata. e. Habit; f-h. Tournefortia rubicunda. f. Inflorescence. g. Flowers. h. Fruit (Photographs: e. M.W.S. Lucas, others D. F. Peralta). 

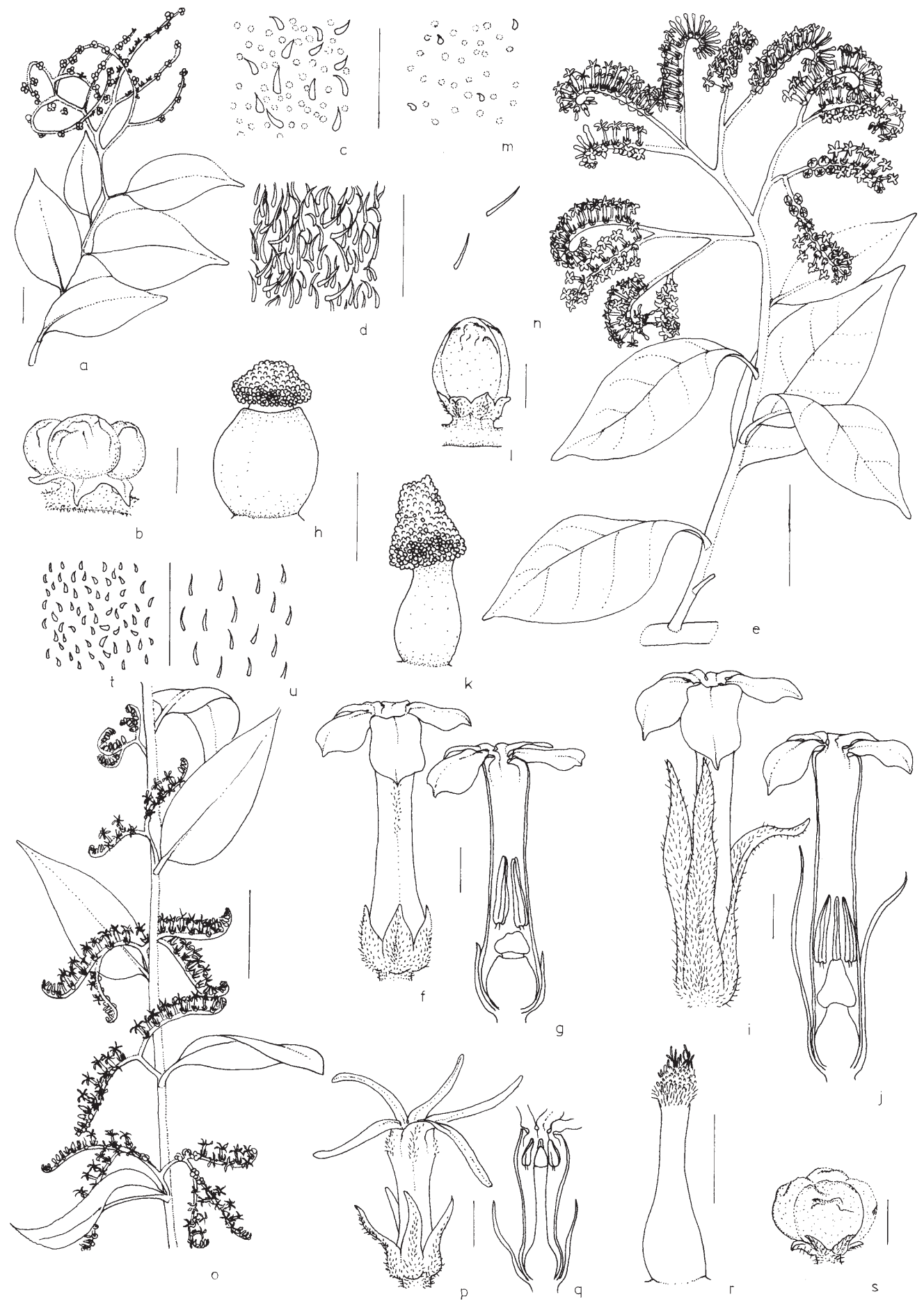

Figura 2. Espécies de Tournefortia do Brasil extra-amazônico. a-d. Tournefortia angustiflora. a. Hábito. b. Fruto seco. c. Superfície adaxial da folha. d. Superfície abaxial da folha. e-n. Tournefortia bicolor. e. Hábito. f. Padrão floral 1. g. Flor em secção longitudinal. h. Gineceu. i. Padrão floral 2. j. Flor em secção longitudinal. k. Gineceu. 1. Fruto seco. m. Superfície adaxial da folha. n. Superfície abaxial da folha. o-u. Tournefortia breviflora. o. Hábito. p. Flor. q. Flor em secção longitudinal. r. Gineceu. s. Fruto. t. Superfície adaxial da folha. u. Superfície abaxial da folha (barras de escala: hábito $2 \mathrm{~cm}$, demais $1 \mathrm{~mm}$ ).

Figure 2. Extra-amazonian Brazilian species of Tournefortia. a-d. Tournefortia angustiflora. a. Habit. b. Dried fruit. c. Leaf adaxial surface. d. Leaf abaxial surface. e-n. Tournefortia bicolor. e. Habit. f. Flower pattern 1. g. Flower in longitudinal section. h. Gynoecium. i. Flower pattern 2. j. Flower in longitudinal section. k. Gynoeceum. 1. Dried fruit. m. Leaf adaxial surface. n. Leaf abaxial surface. o-u. Tournefortia breviflora. o. Habit. p. Flower. q. Flower in longitudinal section. r. gynoecium. s. Fruit. t. Leaf adaxial surface. u. Leaf abaxial surface (scale bars: $1 \mathrm{~mm}$ except a. e. $\mathrm{o}=2 \mathrm{~cm}$ ). 
Está estreitamente relacionada à T. hirsutissima L. (Johnston $1935 \mathrm{a}, \mathrm{b}$ ). Tais espécies são tratadas como distintas por Nowicke (1969) e Gibson (1970), embora Nash \& Moreno em 1981 tenham posicionado $T$. bicolor como uma forma de T. hirsutissima diferindo entre si porque $T$. bicolor é glabra enquanto que T. hirsutissima é geralmente pubescente. Mais recentemente, Funk et. al. (2007) consideram T. hirsutissima como sinônimo de T. bicolor. Ambas as espécies são largamente difundidas nos neotrópicos (Croat 1978).

Está presente no estado do Amazonas e Pernambuco até Santa Catarina, Guiana e Paraguai (Smith 1970, Funk et al. 2007); estende-se do México à América Central e Índias Ocidentais, do norte ao oeste da América do Sul (Miller 1988). No material analisado temos floração praticamente o ano todo e frutificação nos meses de setembro a novembro, janeiro a março e em julho.

Foi encontrada em mata pluvial, mata estacional semi-decídua, mata sub-caducifolia degradada, mata ciliar, restinga, capoeira, várzea e em floresta inundada (material amazônico) e em uma plantação de cacau; ruderais em beira de estrada, hortas e ainda cultivadas em jardins.

4. Tournefortia breviflora DC., Prodr. 9: 520. 1845. Figura $1 \mathrm{c}-\mathrm{d}, 2$ o-s

Lianas, arbustos ou subarbustos escandentes, raro arvoretas, até $2,5 \mathrm{~m}$; ramos glabrescentes a pubescentes. Folhas lanceoladas, elípticas ou ovadas $(1,0) 4,0-7,5(9,5) \mathrm{cm} \times(0,5) 1,5-2,5(4,0) \mathrm{cm}$, ápice acuminado a cuspidado, base aguda, acuminada ou obtusa, margem inteira a levemente ondulada; face adaxial glabrescente a pubescente, face abaxial pouco pubescente a tomentosa, tricomas concentrados na nervura principal; pecíolo muito curto 5-7(-10) $\mathrm{mm}$. Inflorescência axilar laxamente escorpióide, cimas de flores delicadas $(2,0) 3,5-8,0(9,5) \mathrm{cm}$. Flores pediceladas brancas, amarelas, amarelo-esverdeadas ou verdes 3-5(-7) mm; cálice pubescente, tubo ausente ou muito curto não atingindo $1 \mathrm{~mm}$, lobos unidos somente na base, 1-2 mm, lanceolados, atingindo até a metade do tubo da corola; corola pubescente, tubo cilíndrico levemente dilatado na base, 2,5-4,0 mm, lobos ligulados, alongados, 1,5-4,0 mm; anteras coerentes, lanceoladas, inseridas na extremidade do tubo da corola, $1 \mathrm{~mm}$; gineceu 2-4 mm, estigma com um anel estigmático inconspícuo, ápice estigmático cônicotriangular curto, obscuramente 4-lobado, estilete curto até $3 \mathrm{~mm}$. Frutos imaturos verdes, $4-5 \mathrm{~mm}$, fortemente 4-lobados, glabros, embrião curvo.

Material selecionado: BRASIL. AlagoAs: São Miguel dos Campos, X-1980, O. Viégas et al. s.n. (MAC7436). BAhia: Santa Terezinha, VIII-1996, I. Aragão 2 (HUEFS). Distrito Federal: Brasília, IX-1997, A.B. Sampaio et al. s.n. (CEN33414, SJRP26148). Minas Gerais: Fervedouro, VII-1999, J.A. Lombardi 3082 (BHCB, SJRP). PARANÁ: Londrina, VII-1989, L.H. Soares-Silva et al. 224 (FUEL). Rio de JANEIRo: Nova Friburgo, V-1988, G. Martinelli et al. 12885 (RB). Rio Grande Do Sul: Camaquã/Pacheca, X-1989, J.A. Jarenkow et al. 1376 (PEL). Santa Catarina: Itajaí, s.d., Muller 115 (R). São PAulo: São Paulo, X- 2003, L. Cavalheiro et al. s.n. (SJRP26791).

T. breviflora DC. é facilmente reconhecida por suas inflorescências axilares de flores laxamente dispostas nos ramos. O material analisado evidencia floração nos meses de abril a dezembro; frutificação de julho a outubro, março e maio. De acordo com Johnston (1930), esta espécie ocorreria apenas ao longo da costa do Brasil, ao sul de Minas Gerais a Santa Catarina até o Acre e Paraguai. Ocorre também no Peru (Macbride 1960).

De todos os sinônimos listados em Johnston (1930) apenas T. xapuryensis Vaupel mereceu uma nota em particular do autor, pois seu tipo foi coletado nas origens de um rio na Amazônia, no sudoeste do Brasil. Pela sua distribuição inesperada, o autor não pode separar materiais dessa espécie das plantas frequentemente coletadas na costa brasileira e adjacências do Paraguai, mas considerou que talvez novas coletas dessa forma no Estado do Acre pudessem revelar caracteres que a considerariam como distinta. Não foram analisados materiais dessa região o que evidencia a necessidade de maiores coletas.

O material analisado ampliou a distribuição dessa espécie. Citada por Johnston como restrito à costa (com exceção das coletas no Estado no Acre), entretanto, nota-se uma clara distribuição no interior do país além da Argentina; ocorrendo em diversos habitats além da mata atlântica como mata de galeria, mata ciliar, área de várzea, além de espécimes coletados em beira de estradas e cultivados nos jardins das casas.

5. Tournefortia candidula (Miers) I.M. Johnst., Contr. Gray Herb. 5(92): 84. 1930.

Figura 3 a-g. 
Arbustos, subarbustos escandentes ou raro lianas, 0,7-1,7 m; ramos com pubescência esbranquiçada. Folhas lanceoladas, oblongo-lanceoladas a elípticas $(1,5) 2,5-6,0(9,5) \mathrm{cm} \times(0,5) 1,0-3,5(4,0) \mathrm{cm}$, discolores, ápice agudo ou acuminado, base atenuada, margem inteira; face adaxial tomentosa, às vezes tricomas com bases dilatadas, face abaxial mais pálida, densamente vilosa, cinérea ou esbranquiçada; pecíolo delgado geralmente não atingindo $5 \mathrm{~mm}$. Inflorescência terminal, paniculada, flores agregadas em cimas muito curtas, 1,0-2,5 cm. Flores brancas, verdes, amarelas ou até mesmo arroxeadas 3,0-6,0 mm; cálice densamente viloso, tubo curto até $1 \mathrm{~mm}$, lobos alongados atingindo a extremidade do tubo da corola, até $4 \mathrm{~mm}$; corola densamente vilosa, tubo cilíndrico dilatado na base, 2,0-3,5 mm, lobos ovalados, até $2 \mathrm{~mm}$; anteras coerentes, ovóides, inseridas na extremidade do tubo da corola, $1 \mathrm{~mm}$; gineceu 2-3 mm, estigma com anel estigmático evidente, ápice cônico-triangular alongado, obscuramente 4-lobado, estilete curto $1 \mathrm{~mm}$. Frutos imaturos verdes e maduros brancos com manhas negras, ou amarelados, 4-6 mm, fortemente 4- lobados, tomentosos, embrião curvo.

Material selecionado: BRASIL. BAHIA: Alagoinhas, I-2000, F. França et al. 3215 (HUEFS). CEARÁ: Ubajona, IX-1994, F.S. Araújo 951 (UEC). Maranhão: São Luiz, XII-1951, R.L. Froés 27780 (UB). PERNAMBUCO: Itamaracá, I-1986, C.F. Gallindo 156 (IPA). RIO DE JANEIRO: Ilha do Fundão, V-1927, J. Vidal s.n. (R23068). Rio Grande do Norte: Natal, XII-1979, F. Freitas Filho 11086 (UEC). São PAulo: Igaraçaba, s.d., W. Marcondes-Ferreira et al. 1142 (SJRP, SP).

Espécie reconhecível pela pubescência alva que recobre a superfície abaxial foliar e tubo da corola, conferindo-lhe um aspecto prateado (cinéreo) para as folhas. Encontrada em diversos tipos de habitat, concentrando-se em ambientes de climas secos: caatingas, campos rupestres, cerrados, dunas e restingas.

Ocorre na Venezuela, Guiana e no leste do Brasil, do Maranhão ao Rio de Janeiro (Johnston 1930, Funk et al. 2007, Hokche 2008), mais concentrada na Região Nordeste do país. A floração ocorre praticamente o ano todo, com picos de fevereiro a maio.

6. Tournefortia gardneri A. DC., Prodr. Syst. Nat. Regni Veg. 9: 526. 1845.

Figura 3 n-t.
Subarbustos ou arbustos escandentes, até $1 \mathrm{~m}$; ramos pubescentes a tomentosos. Folhas ovadas, lanceoladas a elíptico-lanceoladas $(1,5) 3,0-9,0(11,0) \mathrm{cm}$ $\times(0,5) 1,5-4,0(5,5) \mathrm{cm}$, ápice acuminado ou cuspidado até abruptamente agudo, base acuminada a obtusa, margem inteira; face adaxial hirsutulosa com concentração nas nervuras ou estrigosa e face abaxial amarelo-tomentosa; pecíolo robusto 3-8 $\mathrm{mm}$. Inflorescência terminal, paniculada ou, ainda, terminal a ramos curtos com flores agregadas formando cachos, cimas muito curtas 1,0-2,5 cm. Flores curto-pediceladas ou sésseis, 4-6 mm, alvacentas, amarelas ou esverdeadas, densamente pubescentes a tomentosas; cálice curto, tomentoso, lobos alongados ligulados atingindo a extremidade do tubo da corola, 1,5-3,5 mm; corola tomentosa, tubo dilatado na base, até $4,5 \mathrm{~mm}$, lobos curtos, ligulados, 1,5-2 mm; anteras coerentes, lanceoladas, inseridas na extremidade do tubo da corola, $1,5 \mathrm{~mm}$; gineceu pouco menor que o tubo da corola, $3 \mathrm{~mm}$, estigma com anel estigmático inconspícuo, ápice cônico-triangular curto, obscuramente 4-lobado, estilete delgado 1-1,5 mm. Frutos verdes, 4-7 mm, fortemente 4-lobados, levemente estrigosos, embrião curvo.

Material selecionado: BRASIL. BAHIA: São Sebastião do Passé, VI-1999, F. França et al. 2997 (HUEFS). Rio DE JANEIRO, Rio de Janeiro: X-1969, D. Sucre 6110 (SJRP, RB). SANTA Catarina: s/ localidade, XI-1950, A.P. Duarte et al. 3136 (RB). São Paulo: Iguape, XII-1992, E.A. Anunciação et al. 142 (SP).

T. gardneri é reconhecida principalmente pelas inflorescências congestas, folhas amarelo-tomentosas e pelo fruto levemente estrigoso.

Segundo Johnston (1930), ocorre duas variantes morfológicas quanto ao indumento, há espécimes levemente pubescentes e outros abundantemente estrigosos; as amostras estudadas pertencem ao segundo tipo. Pode ser encontrada no Rio de Janeiro até o Rio Grande do Sul, especialmente na zona marítima (Smith 1970, Guimarães et al. 1971), porém nota-se pelo material examinado que a espécie se estende até a Bahia. A floração ocorre de julho a novembro; frutificação de setembro a novembro. Encontrada nos habitats de mata atlântica e restinga.

7. Tournefortia melanochaeta DC., Prodr. Syst. Regni Veg. Nat. 9: 520. 1845.

Figura $3 \mathrm{u}$-a1. 


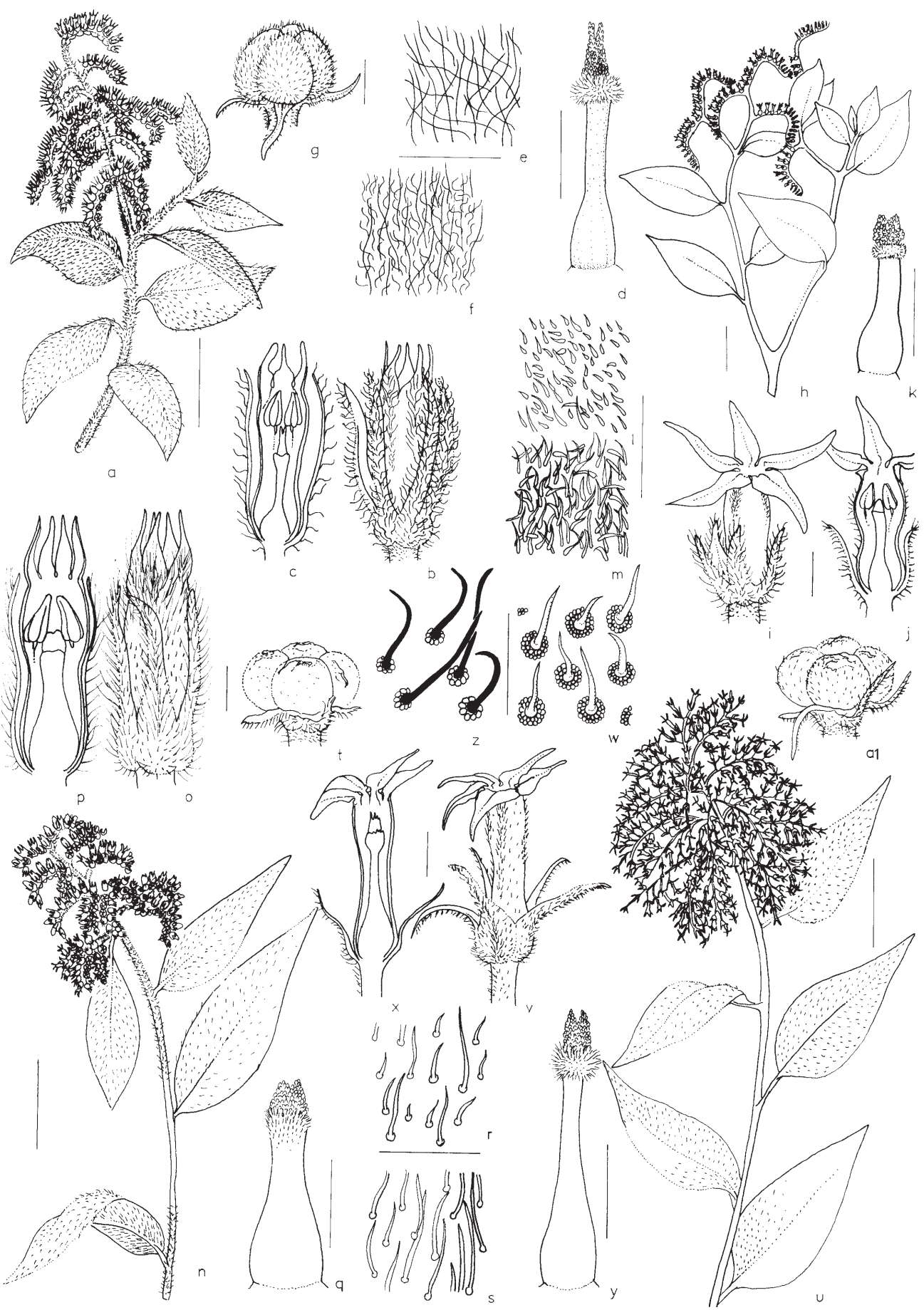

Figura 3. Espécies de Tournefortia do Brasil extra-amazônico. a-g. Tournefortia candidula. a. Hábito. b. Flor. c. Flor em secção longitudinal. d. Gineceu. e. Superfície adaxial da folha. f. Superfície abaxial da folha. g. Fruto. h-m. Tournefortia volubilis. h. Hábito. i. Flor. j. Flor em secção longitudinal. k. Gineceu. 1. Superfície adaxial da folha. m. Superfície abaxial da folha. n-t. Tournefortia gardneri. n. Hábito. o. Flor. p. Flor em secção longitudinal. q. Gineceu. r. Superfície adaxial da folha. s. Superfície abaxial da folha. t. Fruto. u-a1. Tournefortia melanochaeta. u. Hábito. v. Flor. w. superfície abaxial da folha. x. Flor em secção longitudinal. y. Gineceu. z. Superfície adaxial da folha. a1. Fruto (barras de escala: hábito $2 \mathrm{~cm}$, demais $1 \mathrm{~mm}$ ).

Figure 3. Extra-amazonian Brazilian species of Tournefortia. a-g. Tournefortia candidula. a. Habit. b. Flower. c. Flower in longitudinal section. d. Gynoecium. e. Leaf adaxial surface. f. Leaf abaxial surface. g. Fruit. h-m. Tournefortia volubilis. h. Habit. i. Flower. j. Flower in longitudinal section. k. Gynoecium. 1. Leaf adaxial surface. m. Leaf abaxial surface. n-t. Tournefortia gardneri. n. Habit. o. flower. p. Flower in longitudinal section. q. Gynoecium. r. Leaf adaxial surface. s. Leaf abaxial surface. t. Fruit. u-a1. Tournefortia melanochaeta. u. Habit. v. Flower. w. leaf abaxial surface. x. Flower in longitudinal section. y. Gynoecium. z. Leaf adaxial surface. a1. Fruit (scale bars: habit $2 \mathrm{~cm}$, others $1 \mathrm{~mm}$ ). 
Lianas ou arbustos volúveis; ramos estrigosos com tricomas castanho-escuros. Folhas lanceoladas, elíptico-lanceoladas ou obovadas $(3,5) 6,5-10,5 \mathrm{~cm} \times$ $(1,5) 2,5-3,5(6,0) \mathrm{cm}$, ápice agudo a cuspidado, base acuminada a atenuada, margem inteira; face adaxial estrigosa geralmente com tricomas alvos de bases dilatadas, face abaxial castanho-estrigosa, tricomas concentrados nas nervuras, indumento estrigoso com tricomas de bases dilatadas; pecíolo até $7 \mathrm{~mm}$. Inflorescência terminal, paniculada, flores congestas, cimas curtas até $2 \mathrm{~cm}$. Flores pubescentes, verdes ou avermelhadas na maturidade, $5 \mathrm{~mm}$; cálice pubescente, tubo até $2 \mathrm{~mm}$, lobos alongados atingindo a extremidade do tubo da corola, 3-5 mm; corola pubescente, tubo cilíndrico dilatado na base até $3 \mathrm{~mm}$, lobos lanceolados até $4 \mathrm{~mm}$; anteras coerentes, ovóides, inseridas na extremidade do tubo da corola, $1 \mathrm{~mm}$; gineceu $2 \mathrm{~mm}$, estigma com anel estigmático evidente, ápice globoso curto, obscuramente 4-lobado, estilete até $1 \mathrm{~mm}$. Frutos imaturos verdes, até $8 \mathrm{~mm}$, fortemente 4-lobados, estrigosos, embrião curvo.

Material selecionado: BRASIL. BAHIA: Ilhéus, V-2000, M.M. Silva et al. 385 (HUEFS).

Tournefortia melanochaeta é reconhecida pelo aspecto áspero de suas folhas e flores, devido ao indumento estrigoso com tricomas de bases dilatadas, castanho-escuros ou esbranquiçados, sendo relacionada morfologicamente à T. cuspidata Kunth, porém diferenciam-se na pilosidade mais escura e mais rígida de $T$. melanochaeta.

Relatada para Guiana (Funk et al. 2007) e, no Brasil, ocorre no estado da Bahia, em resquícios de Mata Higrófila. A floração ocorre de janeiro a maio e em outubro.

8. Tournefortia membranacea (Gardn.) DC., Prodr. Syst. Nat. Regni Veg. 9: 530. 1845.

Figura 4 a-g.

Arbustos, subarbustos escandentes ou lianas, até 1,2 m; ramos amarelo-pubescentes a tomentosos. Folhas membranáceas, lanceoladas, ovadas, ovaladas, $(1,5) 3,5-5,0(12,5) \mathrm{cm} \times(0,5) 2,5-3,5(5,5) \mathrm{cm}$, ápice acuminado, agudo, cuspidado ou caudado, raro mucronuladas, base obtusa ou acuminada, margem inteira; face adaxial hirsuta, pubescente até tomentosa, tricomas raramente com bases dilatadas, face abaxial densamente pubescente ou tomentosa, ambas faces com tricomas concentrados nas nervuras principal e secundárias; pecíolo $7 \mathrm{~mm}(2 \mathrm{~cm})$. Inflorescência terminal, escorpióide, de flores mais ou menos congestas, cimas curtas, delicadas, 1,5-4,5 cm. Flores sésseis, alvas, amarelas ou verdes até $8 \mathrm{~mm}$; cálice pubescente, tubo muito curto até $0,5 \mathrm{~mm}$, lobos curtos até $2 \mathrm{~mm}$; corola pubescente, tubo cilíndrico, longo, até $6 \mathrm{~mm}$, lobos muito curtos, ovalados, até $2 \mathrm{~mm}$; anteras coerentes, lineares, inseridas na extremidade do tubo da corola, $1 \mathrm{~mm}$; gineceu até $5 \mathrm{~mm}$, estigma com anel estigmático inconspícuo, ápice cônicotriangular curto, evidentemente 4-lobado, estilete até $3 \mathrm{~mm}$. Frutos imaturos verdes, $5 \mathrm{~mm}$, fortemente 4-lobados, glabros, embrião curvo.

Material selecionado: BRASIL. BAHIA: Salvador, I-2001, F.P. Fonseca Neto 42 (HRB). CEARÁ: Serra da Pacatuba, X-1979, P. Martins et al. s.n. (IBGE8544). Espírito SANTO: São Mateus, XII-1994, J.R. Pirani et al. 3328 (NY). Minas Gerais: Passa Quatro, X-1948, J. Vidal 2072 (R). Pernambuco: Bezerros, II-1986, F. Gallindo et al. 1 (IPA). RIO DE JaneIro: Maricá, XI-1988, A. Souza et al. 2233 (R). Rio Grande do Sul: Porto Belo, III-1957, L.B. Smith et al. 12318 (R). SANTA Catarina: Barra Velha, XI-1977, L.R. Landrum 2582 (NY). São Paulo: Itanhaém, IV-1996, V.C. Souza et al. 11090 (ESA, SJRP, SP, SPF).

T. membranacea é reconhecível por suas folhas delicadas (membranáceas) e pela intensa pubescência amarelada na face abaxial. Já foi considerada como uma forma local de T. salzmanii, mas difere desta por ser menos pubescente, possuir flores pequenas de lobos curtos (Johnston 1930) e apresentar ápice estigmático alongado, diferentemente desta. Já com T. volubilis L. está separada pelo hábito arbustivo e por suas folhas mais obtusas.

Para o Brasil é citada para a costa dos estados do Rio de Janeiro e São Paulo. Este trabalho amplia a sua distribuição para o nordeste do país (Bahia, Ceará e Pernambuco) e Região Sul (Paraná, Santa Catarina e Rio Grande do Sul), além de todos os outros estados do Sudeste (Espírito Santo e Minas Gerais).

Segundo Smith (1970), essa espécie restringia-se aos ambientes de vegetação arbustiva, entretanto, o material analisado ocorre, principalmente, nos habitats de mata, tanto em formações primárias quanto secundárias, e restinga, além de capoeiras e nos campos rupestres. Floração de outubro a janeiro, abril a junho.

9. Tournefortia paniculata Cham., Linnaea 4: 468. 1829. 
Arbustos escandentes ou lianas, menores que $1 \mathrm{~m}$ a 1,5-3,0 m; ramos pubescentes ou glabrescentes. Folhas ovadas, ovaladas, elíptico-lanceoladas até largamente lanceoladas $(2,5) 3,5-8,5(14,5) \mathrm{cm} \times$ $(0,5) 1,5-5,0(6,5) \mathrm{cm}$, ápice agudo, acuminado ou cuspidado, base agudaa, obtusa, acuminada a pouco atenuada, margem inteira a levemente ondulada; face adaxial glabrescente, hírtela a pouco pilosa ou pubescente (variedade), tricomas concentrados nas nervuras, face abaxial híspida, pilosa a tomentosa, pilosidade concentrando-se nas nervuras; pecíolo geralmente grande 1-2 cm. Inflorescência terminal, paniculada, laxas, cimas muito ramificadas, $2,5-6,5 \mathrm{~cm}$ ou longas e delicadas, $3-7 \mathrm{~cm}$. Flores pubescentes a tomentosas, 0,4-1 cm, creme, esverdeadas, amareloesverdeadas a branco-amareladas; cálice pubescente, tubo muito curto ou ausente, até 0,5 $\mathrm{mm}$ (alcançando $1 \mathrm{~mm}$ na variedade), lobos curtos, lanceolados, 1-2 mm; corola pubescente a tomentosa com tubo longo dilatado na base, (3,0)5,5-7,5 mm, lobos curto-ovados, ligulados até lanceolados, 1-3 mm; anteras coerentes, lanceoladas, inseridas na extremidade do tubo da corola, $(1,0) 1,5 \mathrm{~mm}$; gineceu longo, (2,5)5,5-7,0 mm, pouco menor que o tubo da corola, estigma com anel estigmático evidente, ápice estigmático globoso, obscuramente 4-lobado, estilete delgado alongado, $(1,0-2,0) 3,0-5,5 \mathrm{~mm}$. Frutos imaturos verdes e maduros alaranjados com manchas negras, 3,5-5,5 mm, fortemente 4-lobados, glabros, embrião curvo.

T. paniculata é caracterizada, principalmente, pela inflorescência paniculada e pelas pontuações esbranquiçadas nas folhas de quase todos os espécimes, sendo, portanto, um importante caráter na identificação desta espécie.

É espécie semelhante à T. maculata Jacq., ocorrente do Acre ao Rio de Janeiro, entretanto, diferem por suas folhas com ápice cuspidado a caudado e nervuras evidentemente marcadas pela concentração da pilosidade.

É amplamente distribuída no Brasil, estendendose desde o sul do Amazonas até o Rio Grande do Sul. $\mathrm{Na}$ América ocorre ainda na Guiana, Colômbia e ao leste do Peru (Brade 1932); e na Bolívia, Paraguai e Argentina (Johnston 1930, Killeen et al. 1993, Funk et al. 2007). Neste mesmo trabalho, Brade cita que a espécie está ausente ao leste do Brasil, entretanto, as coletas aqui apresentadas, demonstram o seu equívoco. O mesmo autor, ainda, menciona variantes morfológicas da espécie ocorrendo no noroeste da Argentina (T. paniculata var. austrina Johnst.), leste do Peru, Colômbia e Guiana Britânica (sinônimo Tournefortia spigelliflora A. DC.). No presente trabalho foram analisadas duas amostras dessa primeira variedade, uma ocorrente na Argentina (Província de Salta) e outra no Estado da Bahia (Município de Planalto), podendo confirmar a sua ocorrência no Brasil ou, ainda, se tratar de um espécime introduzido/cultivado.

Chave para as variedades de T. paniculata

1. Inflorescência escorpióide, cimas muito ramificadas ..... 9.1. T. paniculata var. paniculata

1. Inflorescência escorpióide, cimas pouco ramificadas.

9.2. T. paniculata var. austrina

\subsection{Tournefortia paniculata Cham. var. paniculata}

Figura 1 e, 4 h-n

Material selecionado: BRASIL. BAHIA: Abaíra, XI-1992, W. Ganev 1538 (HUEFS, K, SPF). Distrito Federal: Brasília, XII-1992, B.A.S. Pereira et al. 2390 (IBGE, RB, SP, US). Espírito SANTo: Santana, XII-1962, J. Mattos et al. 10752 (SP). GoIÁs: Goiânia, XI-1970, J.A. Rizzo 6928 (UFG). Minas Gerais: Rio Acima, XII-1997, M.F. Vasconcelos s.n. (BHCB40302, SJRP24578). Paraná: Tunas do Paraná, XII-1999, J.M. Silva et al. 3133 (HRCB, MBML). Rio de Janeiro: Petrópolis, XII-1992, C.G. Pinto 48 (HRB, HUEFS, RB). Rio Grande do Sul: Gaurama, XII-1996, J.A. Jarenkow 3366 (PEL). SÃo PAulo: Campinas, I-2000, T. Spinelli et al. 212 (UEC).

Observou-se a floração nos meses de setembro a fevereiro e no mês de maio; frutificação de novembro a março e maio. Encontrada principalmente em matas (interior e borda), tanto nas de formação primária quanto nas secundárias; em ambientes de mata atlântica, mata semidecidual, mata ciliar, mata serrana (floresta ombrófila) e até em habitats em regeneração. Também ocorre em capoeiras, hortos e há alguns espécimes cultivados em sítios e encontrados nas pastagens e beira de estrada.

9.2. Tournefortia paniculata var. austrina I.M. Johnst., Contr. Gray Herb. 92: 82. 1930.

Figura 4 o-q

Material examinado: BRASIL. BAHIA: Planalto, IV-1995, E. Melo et al. 1179 (HUEFS). 

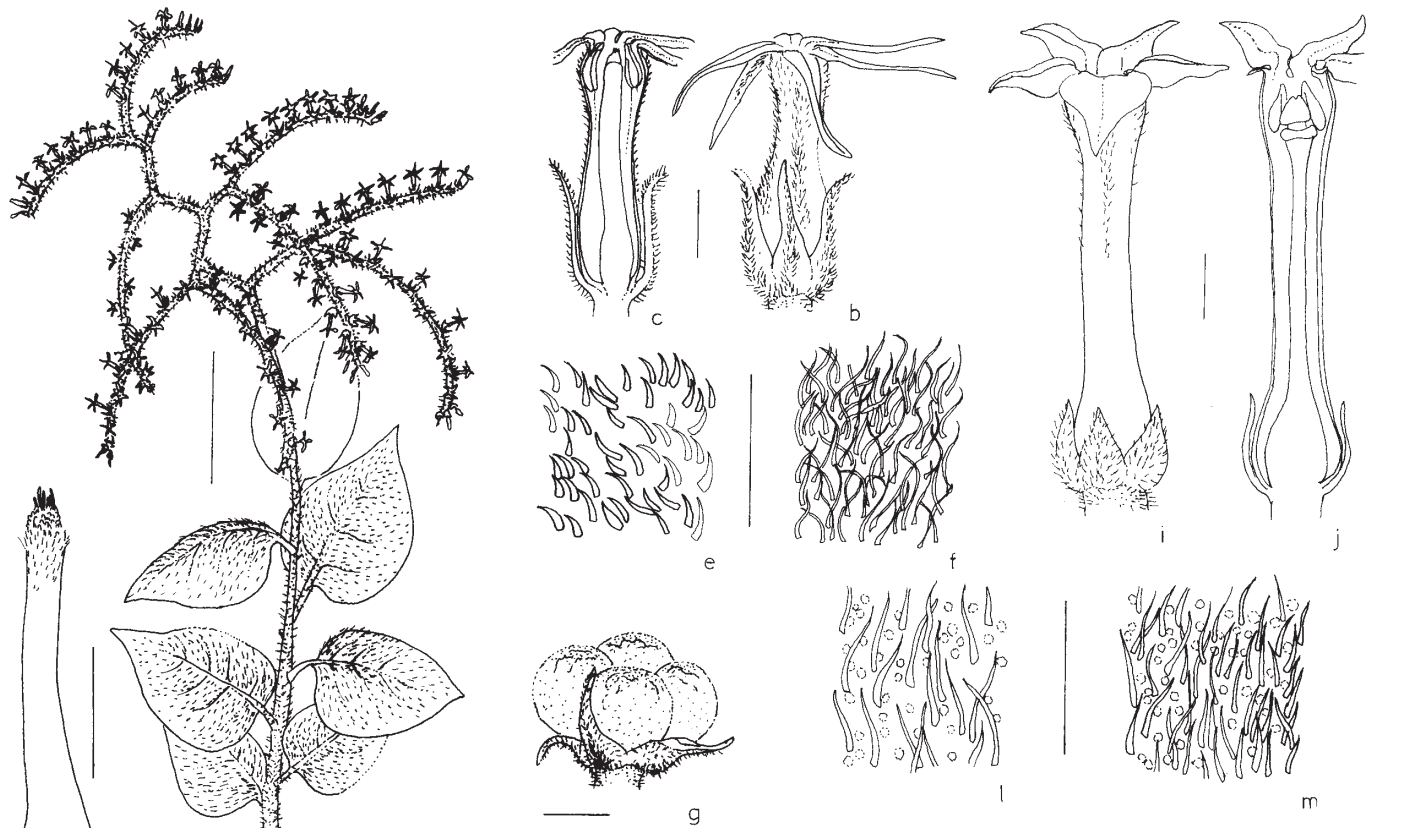
ARGENTINA: Salta, Orán, X-1997, A. Schinini et al. s.n. (HUEFS 35589).

Durante a realização desse estudo foram analisados apenas dois espécimes, um proveniente do Brasil (Bahia) e outro da Argentina, de onde foi originalmente proposta a variedade. É relatada para a Argentina e Bolívia (Perez-Moreau et al. 1983). Diferencia-se da espécie típica pela inflorescência escorpióide de cimas longas com flores laxas e delicadas. A floração ocorre em abril (material brasileiro) e outubro (material argentino). Os habitats não foram mencionados.

10. Tournefortia rubicunda Salzm. ex DC., Prodr. Syst. Nat. Regni Veg. 9: 526. 1845.

Figura $1 \mathrm{f}$-h, 5 a-g.

Arbustos, subarbustos escandentes ou lianas, 0,6-4 m; ramos glabros com lenticelas. Folhas ovadas, ovaladas ou lanceoladas, 3,0-7,5(11,5) cm $\times(1,0) 1,5$ $4,0(7,0) \mathrm{cm}$, ápice abruptamente agudo, acuminado a cuspidado, base aguda, pouco atenuada à obtusa, margem inteira; face adaxial híspida, escabra a estrigosa, face abaxial glabrescente a pilosa, tricomas com bases dilatadas (rubicundos) pelo menos na face abaxial; pecíolo 0,6-1 cm. Inflorescência terminal, escorpióide ou, ainda, terminal a ramos secundifloros, laxas, cimas delgadas, 2,5-6,5 cm. Flores pubescentes alvas, esverdeadas ou amarelas ou, ainda, vermelhas, até $7 \mathrm{~mm}$, cálice pubescente, tubo nunca atingindo $1 \mathrm{~mm}$, lobos lanceolados 1,5-3,0 mm; corola pubescente, tubo 3,0-4,5 $\mathrm{mm}$, lobos ligulados e alongados 1,5-3,0 $\mathrm{mm}$; anteras coerentes, lineares, inseridas próximas à extremidade apical do tubo da corola, $1 \mathrm{~mm}$; gineceu 2,0-3,5 mm, estigma com um anel estigmático evidente, ápice estigmático cônicotriangular alongado, evidentemente 4-lobado, estilete delgado, 1-2 mm. Frutos imaturos verdes e maduros alvos, amarelos, alaranjados ou vermelhos, cerca $4 \mathrm{~mm}$, fortemente 4-lobados, glabros, embrião curvo.

Material selecionado: BRASIL. Alagoas: Marechal Deodoro, V-1995, R.P. Lyra-Lemos et al. s.n. (MAC8711). BAHIA: Quixaba, I-2001, M.L. Guedes et al. 7923 (ALCB, HUEFS). CEARÁ: Fortaleza, II-1955, A. Ducke 2420 (UB). Distrito Federal: Brasília, VII-1993, E. Melo et al. 872 (HUEFS). Espírito SANTo: Santa Teresa, VI-2000, V. Demuner et al. 1143 (MBML, SJRP). GoiÁs: Alto Paraíso de Goiás, XI-1996, R.C. Mendonça et al. 2935 (IBGE, RB). Minas Gerais: Matozinhos, X- 1996, J.A. Lombardi 1440 (BHCB, SJRP). Mato Grosso Do
Sul: Bonito, IX-1998, G.A. Damasceno Jr. et al. 16667 (HUFU). Paraíba: São José dos Cordeiros, I-1987, E. Braz s.n. (IPA53026). Pernambuco: Caruaru, IV-1991, M.L. Guedes 96 (IPA). ParanÁ: Cascavel, XI-1988, J. Cruz 180 (FUEL). Rio DE JaneIro: Rio de Janeiro, XII-1973, D. Araújo \& A.L. Peixoto 561 (RB). São Paulo: Avaí, VIII-1998, A.P. Bertoncini et al. 856 (SJRP).

Material adicional selecionado: BRASIL. AmAZONAs: Tefé, I-1974, P.L. Krieger et al. 12706 (SJRP, UFJF). ARGENTINA. Misiones: VII-1993, R. Vanni et al. 3281 (SPF). PARAGUAI. Paraguarí: XII-1988, E. Zardini et al. 8670 (UEC).

T. rubicunda é reconhecida pelos tricomas com bases dilatadas presentes na face adaxial e/ou abaxial das folhas.

Ocorre de Pernambuco até o Mato Grosso e no Rio Grande do Sul (Johnston 1930), aqui observada praticamente em todo o país. Também encontrada na Bolívia, Paraguai e norte da Argentina (Smith 1970, Foster 1958, Perez-Moreau et al. 1983).

Nota-se uma grande variedade de cores mencionadas para as flores dessa espécie: roxa, lilás, vermelha, laranja ou castanha as quais provevelmente correspondem ao estado de maturação das mesmas.

A floração foi registrada nos meses de setembro a fevereiro, abril-maio e em julho; frutificação em agosto e nos meses de novembro a junho. Encontrada nos habitats de floresta estacional semidecidual, matas de encosta, primária, ciliar e sub-bosques; estepes, restingas, campos rupestres, capoeiras, caatingas antropizadas a dunas instáveis; ruderais como em pastagem e beiras de estrada além de mata degradada.

11. Tournefortia salicifolia (Gardn.) DC., Prodr. Syst.

Nat. Regni Veg. 9: 526. 1845.

Figura 5 h-n

Arbustos ou subarbustos, até $1 \mathrm{~m}$; ramos pubescentes a rufescentes. Folhas ovadas, lanceoladas $(3,0) 4,0-6,5(9,5) \mathrm{cm} \times(0,7) 1,0-3,0(4,0) \mathrm{cm}$, ápice acuminado a cuspidado, base aguda, acuminada ou obtusa, margem inteira; face adaxial vilosa, face abaxial densamente amarelo-dourado vilosa, às vezes concentrados nas nervuras; pecíolo 5-8 $\mathrm{mm}$. Inflorescência terminal, paniculada, de flores mais ou menos adensadas, cimas $2-3 \mathrm{~cm}$. Flores sésseis, alvas a esverdeadas, 3,5- 5,0 mm; cálice tomentoso, lobos alongados, lineares, 2-3 mm, unidos somente na base, de mesmo tamanho que o tubo da corola ou pouco 
menores; corola tomentosa, tubo dilatado na base 2,5-3,5 mm, lobos curtos, ligulados, 1,0-1,5 mm; anteras coerentes, ovóides, inseridas na extremidade do tubo da corola, $1 \mathrm{~mm}$; gineceu 2,5-3,0 mm, estigma com anel estigmático evidente, ápice cônico-triangular alongado, evidentemente 4-lobado, estilete curto até $1 \mathrm{~mm}$. Frutos imaturos verdes $4 \mathrm{~mm}$, fortemente 4-lobados, estrigosos, embrião curvo.

Material selecionado: BRASIL. Distrito Federal: Brasília, IV-1952, L.B. Smith et al. 6337 (R). PARANÁ: Pambará, XII-1950, G. Hashimoto 677 (SP). Rio DE JANEIRo: Itapuassú, IX-1982, R. Andreata et al. 546 (RB). Rio GRANDE Do Sul: São Leopoldo, I-1903, Emrich et al. s.n. (SP50963).

T. salicifolia é reconhecida por suas folhas densamente amarelo-dourado rufescentes e pela inflorescência mais ou menos adensada. É morfologicamente relacionada $T$. membranacea e T. villosa diferindo destas por suas folhas lanceoladas, inflorescência mais ou menos congesta e lobos do cálice alongados.

A floração e a frutificação ocorrem nos meses de setembro, novembro a janeiro e de março a maio, o que sugere ocorrer durante todo o ano.

Johnston (1930) cita que T. salicifolia está localmente distribuída, conhecida apenas nos arredores do Rio de Janeiro, entretanto, de acordo com o material examinado, ocorre também nos Estados de Goiás, Minas Gerais, Paraná e Rio Grande do Sul.

12. Tournefortia salzmannii DC., Prodr. Syst. Nat. Regni Veg. 9: 524. 1845.

Figura 5 o-u.

Arbustos escandentes ou lianas, 0,5-3 m; ramos tomentosos, com lenticelas. Folhas ovadas ou elípticolanceoladas $3,0-5,5(7,5) \mathrm{cm} \times(1,0) 1,5-3,5 \mathrm{~cm}$, discolores, ápice agudo ou acuminado, base aguda, obtusa a cordiforme, margem inteira; face adaxial hirsuta a tomentosa e abaxial densamente tomentosa, tricomas amarelados ou esbranquiçados; pecíolo robusto, 0,6-1 cm. Inflorescência terminal, escorpióide, raramente axilar, cimas delicadas, 4-8 $\mathrm{cm}$. Flores sésseis, tomentosas, alvas, esverdeadas ou amareladas, até $5 \mathrm{~mm}$; cálice tomentoso, lobos curtolanceolados unidos somente na extremidade do tubo, 1-2 mm; corola tomentosa, tubo dilatado na base, 2,0-3,5 mm, lobos lineares até $2 \mathrm{~mm}$; anteras coerentes, lanceoladas, inseridas na extremidade do tubo da corola, $1 \mathrm{~mm}$; gineceu até $3,5 \mathrm{~mm}$, estigma com anel estigmático evidente, ápice cônico-triangular curto, evidentemente 4-lobado, estilete curto até $1,5 \mathrm{~mm}$. Frutos imaturos verdes e maduros amarelos até $4 \mathrm{~mm}$, fortemente 4-lobados, glabros, embrião curvo.

Material selecionado: BRASIL. BAHIA: Itatim, X-1996, F. França et al. 1921 (HUEFS). CeArÁ: Pacotí, X-1980, E. Nunes et al. s.n. (EAC8949). Espírito SAnto: Santa Teresa, XI-1985, W. Pizziolo 205 (MBML, SJRP). Piauí: Serra Branca, II-1984, L. Emperaire s.n. (RB335024, UFPI2428). RIO DE JANEIRO: Rio de Janeiro, III-1978, P. Laclette et al. 442 (R).

T. salzmanii é reconhecida por suas folhas discolores de aspecto aveludado (tomentosas) e inflorescência longa, tipicamente escorpióide, de flores delicadas, além dos ramos com lenticelas. Foram raramente citadas flores azuis, porém isto não foi observado no material vivo.

Segundo Johnston (1930), ocorre nos estados do Ceará ao Rio de Janeiro, podendo aparecer no extremo norte do país. Também ocorre na Bolívia, Colômbia, Paraguai e ao norte da Argentina (Foster 1958, Perez-Moreau et al. 1983).

Às vezes pode ser confundida com $T$. villosa Salzm. ex DC. diferindo desta pela inflorescência laxamente escorpióide e menos ramificada de T. salzmanii. A floração ocorre de fevereiro a junho, de agosto a dezembro, ou seja, praticamente o ano todo; a frutificação ocorre em agosto e de fevereiro a abril. Encontrada principalmente em caatinga e dunas, entretanto ocorre também em ambientes de mata, como de encosta e mata ciliar; em carrasco, campo rupestre, capoeira e alguns espécimes ruderais.

13. Tournefortia maculata Jacq., Enum. Syst. P1. 14. 1760 .

Figura 6 a-g

Arbusto semi-escandente ou lianas sobre árvores; ramos pubescentes. Folhas obovadas ou lanceoladas $(3,0) 4,0-6,5(9,5) \mathrm{cm} \times(1,5) 2,5-4,0(5,0) \mathrm{cm}$, ápice cuspidado a caudado, base aguda a acuminada, margem inteira; face adaxial e abaxial pubérula, com tricomas concentrados nas nervuras principal e secundárias; pecíolo $1 \mathrm{~cm}(1,5 \mathrm{~cm})$. Inflorescência terminal, paniculada, laxas, cimas até $5 \mathrm{~cm}$. Flores pubescentes, verdes, menores que $1 \mathrm{~cm}$; cálice pubescente, tubo até $0,5 \mathrm{~mm}$, lobos lanceolados $1 \mathrm{~mm}$; corola pubescente, tubo cilíndrico, até $7 \mathrm{~mm}$, lobos 


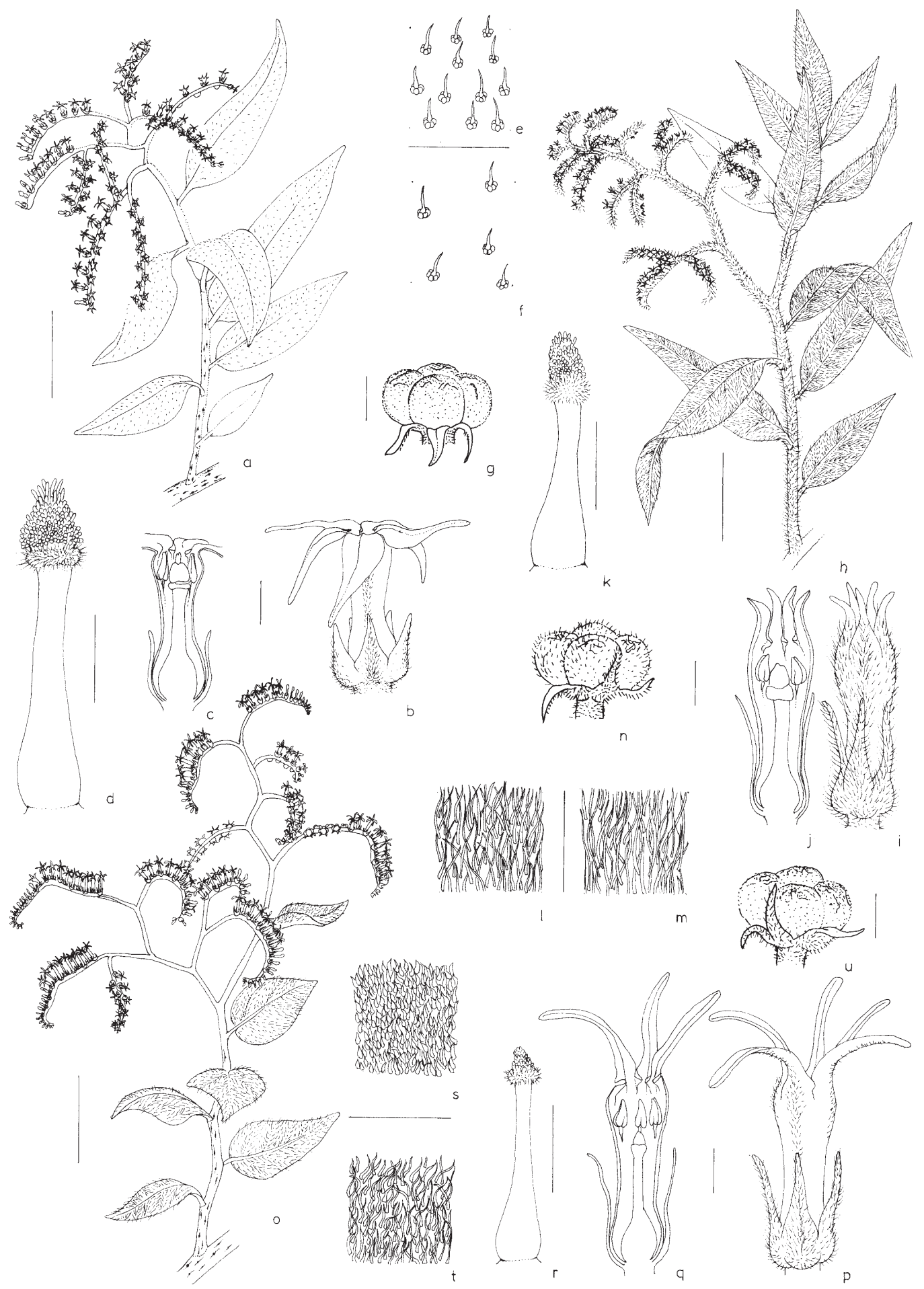

Figura 5. Espécies de Tournefortia do Brasil extra-amazônico. a-g. Tournefortia rubicunda. a. Hábito. b. Flor. c. Flor em secção longitudinal. d. Gineceu. e. Superfície adaxial da folha. f. Superfície abaxial da folha. g. Fruto. h-n. Tournefortia salicifolia. h. Hábito. i. Flor. j. Flor em secção longitudinal. k. Gineceu. l. Superfície adaxial da folha. m. Superfície abaxial da folha. n. Fruto. o-u. Tournefortia salzmannii. o. Hábito. p. Flor. q. Flor em secção longitudinal. r. Gineceu. s. Superfície adaxial da folha. t. Superfície abaxial da folha. u. Fruto (barras de escala: hábito $2 \mathrm{~cm}$, demais $1 \mathrm{~mm}$ ).

Figure 5. Extra-amazonian Brazilian species of Tournefortia. a-g. Tournefortia rubicunda. a. Habit. b. Flower. c. Flower in longitudinal section. d. Gynoecium. e. Leaf adaxial surface. f. Leaf abaxial surface. g. Fruit. h-n. Tournefortia salicifolia. h. Habit. i. Flower. j. Flower in longitudinal section. k. Gynoecium. 1. Leaf adaxial surface. m. Leaf abaxial surface. n. Fruit. o-u. Tournefortia salzmannii. o. Habit. p. Flower. q. Flower in longitudinal section. r. Gynoecium. s. Leaf adaxial surface. t. Leaf abaxial surface. u. Fruit (scale bars: habit $2 \mathrm{~cm}$, others $1 \mathrm{~mm})$. 
ovados até $2 \mathrm{~mm}$; anteras coerentes, lineares, inseridas na extremidade do tubo da corola 1,0-1,5 mm; gineceu até $7 \mathrm{~mm}$, estigma com um anel estigmático evidente, ápice globoso curto, obscuramente 4-lobado, estilete com 5-6 mm. Frutos imaturos verdes, $3 \mathrm{~mm}$, obscuramente 4-lobados, glabros, embrião curvo.

Material selecionado: BRASIL. GoIÁs: São Domingos, X-2000, M. Aparecida-Silva et al. 4579 (IBGE, RB). Minas Gerais: Esperança, I-1916, P. Campos-Porto 452 (RB). Rio de Janeiro: Petrópolis, XII-1992, C.G. Pinto 48 (HRB, HUEFS). Tocantins: Dianópolis, XII-1991, B.A.S. Pereira et al. 1985 (IBGE, RB, UEC, US).

Material adicional examinado: BRASIL. ACRE: Tarauacá, IX- 1968, G.T. Prance et al. 7253 (INPA, K, NY, S, US). Amazonas: Manaus, XII-1976, M.R. Cordeiro 1317 (HRCB).

Espécie morfologicamente semelhante a T. paniculata diferindo no ápice cuspidado de suas folhas e tricomas mais densamente distribuídos, flores com lobos da corola alongados e ápice estigmático curto e globoso. Encontrada na América Central e do Sul, da Bolívia ao norte do Brasil (Miller 1988). No Brasil, ocorre do Acre ao Rio de Janeiro. A floração ocorre de setembro a janeiro, com picos em dezembro; a frutificação não foi mencionada, pois havia apenas um exemplar com frutos, não revelando, assim, o real período de frutificação.

Essa espécie não havia sido citada na última evisão feita para o gênero (Johnston 1930), sendo nesse trabalho uma nova ocorrência para o Brasil.

14. Tournefortia villosa Salzm. ex DC., Prodr. 9: 524. 1845.

Figura 6 h-n

Cipós ou arbustos escandentes, até $3 \mathrm{~m}$; ramos hirsutos a dourado-tomentosos. Folhas lanceoladas, elíptico-lanceoladas ou ovadas, 3,0-7,0(14,0) $\mathrm{cm} \times$ $(1,0) 2,0-4,0(6,0) \mathrm{cm}$, às vezes discolores, ápice agudo a acuminado, base acuminada a obtusa, margem inteira; face adaxial hirsuta, às vezes escabra, com tricomas concentrados nas nervuras, face abaxial densamente dourado vilosa; pecíolo robusto 5-6 $\mathrm{mm}$, podendo chegar a $1 \mathrm{~cm}$. Inflorescência terminal, paniculada, adensada, cimas 1-3 cm. Flores tomentosas, alvas, esverdeadas, amareladas ou creme, 4-6 mm; cálice tomentoso, tubo menor que $1 \mathrm{~mm}$, lobos lanceolados atingindo a extremidade do tubo da corola 2,0-3,5 mm; corola tomentosa, tubo geralmente dilatado na base, 3-4,5 mm, lobos lineares, 1-2 $\mathrm{mm}$; anteras coerentes, lanceoladas, inseridas na extremidade do tubo da corola $1 \mathrm{~mm}$; gineceu 2-3 mm, estigma com anel estigmático inconspícuo, ápice cônico-triangular curto, obscuramente 4-lobado, estilete curto 1,0-1,5 mm. Frutos imaturos verdes e maduros amarelos até $5 \mathrm{~mm}$, fortemente 4-lobados, levemente estrigosos, raramente glabros, embrião curvo.

Material selecionado: BRASIL. BAHIA: Esplanada, II-2002, J.R. Pirani et al. 4968 (SPF). Espírito SANTO: Iúna, XI-1993, G. Hatschbach 1994 (HUEFS, MBML, UB). Minas Gerais: Juiz de Fora, XII-1972, P.L. Krieger 11948 (SJRP, UFJF). Piauí: São José do Piauí, II-2002, M.R.A. Mendes et al. 514 (SJRP, TEPB). Rio DE JANEIRo: Petrópolis, XII-1968, D. Sucre et al. 4202 (RB, SJRP). Sergipe: Salgado, V-1982, G. Viana 488 (UFS). São PAUlo: Restinga, I-1996, V.C. Souza et al. 9770 (ESA).

T. villosa é reconhecível por sua inflorescência paniculada, adensada, e suas folhas douradotomentosas. No Brasil, apresenta ampla distribuição, principalmente na Bahia, Minas Gerais até o Rio Grande do Sul (Smith 1970), entretanto, nesse trabalho, não observadas neste último Estado. Floração de agosto a maio; frutificação de novembro a maio. Encontrada nos ambientes de várzea de mata, mata pluvial, mata de cipó e mata degradada; capoeiras e campos. Johnston (1930) cita que os frutos de T. villosa são glabros, fato presenciado em poucos espécimes coletados.

15. Tournefortia volubilis L., Sp. Pl. 1: 140. 1753. Figura 3 h-m.

Sem porte especificado; ramos amarelos, pubescentes. Folhas ovaladas 3,0-6,0 cm $\times 2,0-3,5 \mathrm{~cm}$, membranáceas, ápice acuminado, base obtusa, margem inteira; face adaxial pubescente com tricomas concentrados na nervura principal e face abaxial densamente amarelo, pubescente; pecíolo até $1 \mathrm{~cm}$. Inflorescência terminal, escorpióide, laxas, em cimas até $4 \mathrm{~cm}$. Flores tomentosas, sésseis, alvas, $5 \mathrm{~mm}$; cálice pubescente, tubo inconspícuo, até $0,5 \mathrm{~mm}$, lobos alongados, lanceolados, $1,5 \mathrm{~mm}$, atingindo a metade do tubo da corola; corola tomentosa, tubo dilatado na base, $3 \mathrm{~mm}$, lobos fortemente alongados, lanceolados, $1,5 \mathrm{~mm}$; anteras coerentes, lanceoladas, inseridas na extremidade do tubo da corola, $1 \mathrm{~mm}$; gineceu 2-3 mm, estigma com anel estigmático evidente, ápice cônicotriangular curto, evidentemente 4-lobado; estilete $1 \mathrm{~mm}$. Frutos não analisados. 


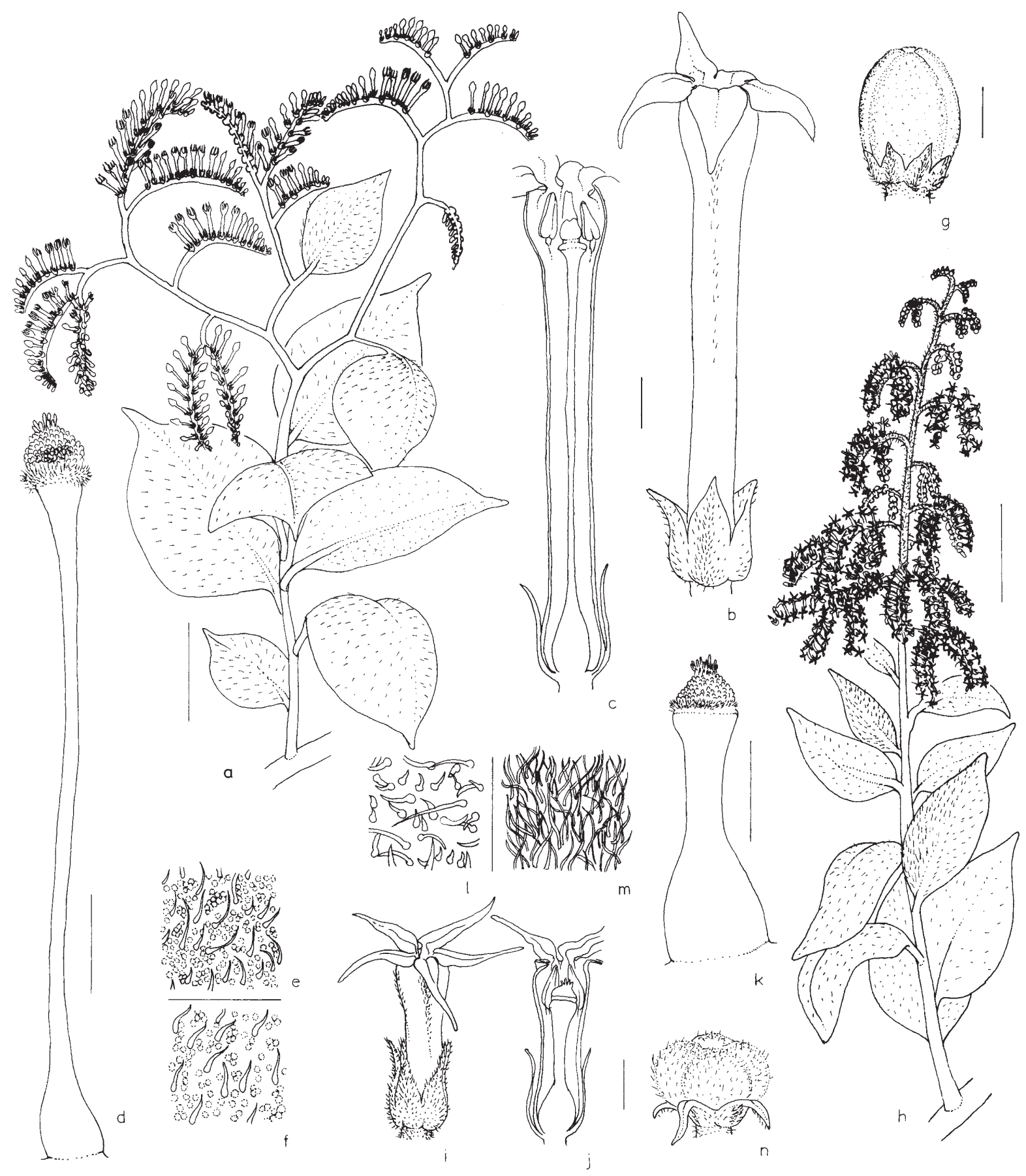

Figura 6. Espécies de Tournefortia do Brasil extra-amazônico. a-g. Tournefortia maculata. a. Hábito. b. Flor. c. Flor em secção longitudinal. d. Gineceu. e. Superfície adaxial da folha. f. Superfície abaxial da folha. g. Fruto. h-n. Tournefortia villosa. h. Hábito. i. Flor. j. Flor em secção longitudinal. k. Gineceu. 1. Superfície adaxial da folha. m. Superfície abaxial da folha. n. Fruto (barras de escala: hábito $2 \mathrm{~cm}$, demais $1 \mathrm{~mm})$.

Figure 6. Extra-amazonian Brazilian species of Tournefortia. a-g. Tournefortia maculata. a. Habit. b. Flower. c. Flower. c. Flower in longitudinal section. d. Gynoecium. e. Leaf adaxial surface. f. Leaf abaxial surface. g. Fruit. h-n. Tournefortia villosa. h. Habit. i. Flower. j. Flower in longitudinal section. k. Gynoecium. 1. Leaf adaxial surface. m. Leaf abaxial surface. n. Fruit (scale bars: habit $2 \mathrm{~cm}$, others $1 \mathrm{~mm}$ ). 
Material examinado: BRASIL. Rio dE JANEIRO: Sem Localidade, s.d., E. Ule 169 (R).

Durante o estudo foi analisado apenas um espécime, coletado por Ule, que não possuía frutos. A floração não estava especificada nem o habitat. Como informação da etiqueta, Ule comenta a distribuição de T. volubilis para a América Tropical, sendo apenas citada por Fresenius na "Flora Brasiliensis", entretanto, relacionada por Johnston como sinônimo de T. membranacea, entretanto distinta desta pelas inflorescências mais adensadas. Nas revisões mais atuais, não há indícios dessa espécie para o Brasil (Johnston 1930, Smith 1970, Guimarães et al. 1971), inclusive na revisão do gênero para a América do Sul (Johnston 1930). Ainda, de acordo com Fresenius (1857), está proximamente relacionada à T. salzmannii, mas diferem por suas folhas levemente acuminadas.

Entre os sinônimos, T. floribunda Kunth merece destaque, pois vem sendo reportada por alguns autores de trabalhos recentes como sinônimo de T. volubilis (Miller 1988, Balick et al. 2000, Stevens et al. 2001, Hokche 2008).

\section{Agradecimentos}

A primeira autora agradece ao Conselho Nacional de Pesquisa (CNPq) pela bolsa de mestrado concedida e aos orientadores Neusa Taroda Ranga e, especialmente, Antonio Furlan (in memorian) pelas valiosas contribuições. Aos diversos herbários do país que disponibilizaram o material estudado. Especial agradecimento a Denilson Fernandes Peralta pelo imenso apoio no desenvolvimento e execução deste trabalho e pelas ilustrações e fotografias.

\section{Literatura citada}

Andrade-Lima, D. 1953. Contribuição para o conhecimento da Flora do Cabo de Santo Agostinho. Base de Dados CNIP - Checklist das Plantas do Nordeste - versão 11.2. http://umbuzeiro.cnip.org.br/db/pnechk/bib/n19.shtml (acesso em 17.3.2002).

Andrade-Lima, D. 1954. Contribution to the study of the Flora of Pernambuco, Brazil. Base de Dados CNIP Checklist das Plantas do Nordeste - versão 11.2. http:/ /umbuzeiro.cnip.org.br/db/pnechk/bib/n21.shtml (acesso em 17.3.2002).

Balick, M.J., Nee, M.H. \& Atha, D.E. 2000. Checklist of the vascular plants of Belize. Memoirs of the New York Botanical Garden 85: 1-246.
Brade, A.C. 1932. Os gêneros Cordia e Tournefortia. Boletim do Museu Nacional do Rio de Janeiro 8: 13-47.

Cavalheiro, L., Peralta, D.F. \& Furlan, A. 2003. Flórula fanerogâmica da planície litorânea de Picinguaba, Ubatuba, SP, Brasil: Boraginaceae. Hoehnea 30(3): 173-179.

Croat, T.B. 1978. Flora of Barro Colorado Island. Stanford University Press, Stanford.

Diane, N., Förther, H. \& Hilger, H.H. 2002. A systematic analysis of Heliotropium, Tournefortia and allied taxa of the Heliotropiaceae (Boraginales) based on ITS1 sequences and morphological data. American Journal of Botany 89: 287-295.

Foster, R.C. 1958. A catalogue of the ferns and flowering plants of Bolivia. Contribution of the Gray Herbarium 184: $1-223$

Fresenius, G. 1857. Cordiaceae Heliotropieae et Boragineae In: C.F.P Martius, A.G. Eichler \& I. Urban (eds.). Flora Brasiliensis, Typographia Regia, Monachii, v. 8 pp. $1-63$.

Funk, T.H., Hollowell, V., Berry, P.E., Kelloff, C. \& Alexander, S. 2007. Checklist of the Plants of the Guiana Shield (Venezuela: Amazonas, Bolivar, Delta Amacuro; Guyana, Surinam, French Guiana). Contribution From the United States National Herbarium 55: 1-584.

Gentry, A.H. 1977. New species of Gibsoniothamnus (Scrophulariaceae/Bignoniaceae) and Tournefortia (Boraginaceae) from Eastern Panama and the Chocó. Annals of the Missouri Botanical Garden 64: 133-135.

Gibson, D.N. 1970. Boraginaceae. Fieldiana, Botany 24: 111-167.

Guimarães, E.F., Barroso, G.M., Falcão-Ichaso, C.L. \& Bastos, A.R. 1971. Flora da Guanabara: Flacourtiaceae, Olacaceae, Boraginaceae. Rodriguesia 26: 142-246.

Hickey, M. \& King, C. 2002. Illustrated glossary of botanical terms. 2 ed. Cambridge University Press, Cambridge.

Hokche, O., Berry, P.E. \& Otto, H. 2008. Nuevo catalogo flora vascular de Venezuela Fundación Instituto Botánico de Venezuela Dr. Tobías Lasser. Caracas.

Johnston, I.M. 1930. Studies in the Boraginaceae, VIII. Observations on the species of Cordia and Tournefortia known from Brazil, Paraguay, Uruguay, and Argentina. Contribution of the Gray Herbarium 92: 3-89.

Johnston, I.M. 1935a. Studies in the Boraginaceae X: The Boraginaceae of northeastern South America. Journal of the Arnold Arboretum 16: 1-64.

Johnston, I.M. 1935b. Studies in the Boraginaceae, XI. (1) The species of Tournefortia and Messerschmidtia in the Old World. (2) Notes on Brand's treatment of Cryptantha (3) New or otherwise noteworthy species. Journal of the Arnold Arboretum 16: 145-205. 
Jorgensen, P.M. \& León-Yánez, S. 1999. Catalogue of the vascular plants of Ecuador. Monographs in Systematic Botany from the Missouri Botanical Garden 75: 1-1181.

Killeen, T.J., García Estigarribia, E. \& Beck, S.G. 1993. Guia de arboles de la Bolivia. Insituto de Ecologia, La Paz.

Lawrence, J.R. 1937. A correlation of the taxonomy and the floral anatomy of certain Boraginaceae. American Journal of Botany 24: 433-444.

Linares, J.L. 2003. Listado comentado de los árboles nativos y cultivados en la república de El Salvador. Ceiba 44: 105-268.

Macbride, J.F. 1960. Boraginaceae In: J.F. Macbride (ed.). Flora of Peru. Fieldiana: Botany 13: 539-609.

Melo, J.I.M. 2007. Uma nova espécie de Tournefortia L. (Boraginaceae s.l.) para o Nordeste do Brasil. Hoehnea 34: $155-158$

Melo, J.I.M. \& Andrade, W.M. 2007. Boraginaceae s.l. A. Juss. em uma área de Caatinga da ESEC Raso da Catarina, BA, Brasil. Acta Botanica Brasilica 21:369-378.

Melo, J.I.M., Paulino, R.C. \& Silva, F.K. 2007. Chave ilustrada para os gêneros de Boraginaceae senso lato nativos do Brasil. Revista Caatinga 20: 172-180.

Melo, J.I.M. \& Lyra-Lemos, R.P. 2008. Sinopse taxonômica de Boraginaceae sensu lato A. Juss. no Estado de Alagoas, Brasil. Acta Botanica Brasilica 22: 701-710.

Miller, J.S. 1988. A revised treatment of Boraginaceae for Panama. Annals of the Missouri Botanical Garden 75: 456-521.
Nagatani, Y. \& Rossi, L. 2000. Flora Fanerogâmica do Parque Estadual das Fontes do Ipiranga: 141-Boraginaceae. Hoehnea 27: 95-98.

Nash, D.L. \& Moreno, N.P. 1981. Boraginaceae. Flora de Veracruz 18: 1-149.

Nicolson, D.H. 1995. Proposals to conserve or reject. Taxon 44: 607-612.

Nowicke, J.W. 1969. Flora of Panama, Part VIII. Family 167. Boraginaceae. Annals of the Missouri Botanical Garden 56:33-69.

Perez-Moreau, R.L. \& Cabrera, A.L. 1983. Boraginaceae in A. L. Cabrera. Fl. Prov. Jujuy 13(8): 247-291.

Renner, S.S., Balslev, H. \& Holm-Nielsen, L.B. 1990. Flowering plants of Amazonian Ecuador - A checklist. AAU Reports 24: 1-241.

Smith, L.B. 1970. Boragináceas. Flora Ilustrada Catarinense 1: $1-85$.

Stevens, W.D., Ulloa C.U., Pool,A. \& Montiel, O.M. 2001. Flora de Nicaragua. Monograph in Systematic Botany from the Missouri Botanical Garden 85: 1-2666.

Taroda, N. \& Cavalheiro, L. 2002. Boraginaceae. In M.M.R.F. Melo, F. Barros, S.A.C. Chiea, M. Kirizawa, S.L. Jung-Mendaçoli \& M.G.L. Wanderley (eds.). Flora Fanerogâmica da Ilha do Cardoso (São Paulo, Brasil) 9: 105-114.

Vitta, F.A. 1992. Flora da Serra do Cipó, Minas Gerais: Boraginaceae. Boletim de Botânica da Universidade de São Paulo 13: 235-239. 